\title{
Review Article \\ From Plastic to Silicone: The Novelties in Porous Polymer Fabrications
}

\author{
Soumaya Berro, ${ }^{1}$ Ranim El Ahdab, ${ }^{2}$ Houssein Hajj Hassan, ${ }^{3}$ \\ Hassan M. Khachfe, ${ }^{3}$ and Mohamad Hajj-Hassan ${ }^{1}$ \\ ${ }^{1}$ Department of Biomedical Engineering, Lebanese International University, Mazraa, P.O. Box 146404, Beirut, Lebanon \\ ${ }^{2}$ Department of Biomedical Engineering, Near East University, Northern Cyprus, Mersin 10, Turkey \\ ${ }^{3}$ Department of Biological and Chemical Sciences, Lebanese International University, Mazraa, P.O. Box 146404, Beirut, Lebanon \\ Correspondence should be addressed to Mohamad Hajj-Hassan; mohamad.hajjhassan@liu.edu.lb
}

Received 9 November 2014; Revised 31 March 2015; Accepted 2 April 2015

Academic Editor: Margarida Amaral

Copyright (C) 2015 Soumaya Berro et al. This is an open access article distributed under the Creative Commons Attribution License, which permits unrestricted use, distribution, and reproduction in any medium, provided the original work is properly cited.

\begin{abstract}
Porous polymers are gaining increased interest in several areas due, in great part, to their large surface area and unique physiochemical properties. Porous polymers are conventionally manufactured using specific processes related to the chemical structure of each polymer. With the wide variety of porous polymers that have been designed, fabricated, and tested to date, this review aims to provide an overview of the advances and recent progress in the preparation processes and fabrication techniques. A detailed comparison between these techniques is also provided. Some of these techniques offer the advantage of controlling the porosity and the possibility to obtain porous $3 \mathrm{D}$ polymers. A new generic fabrication process that can be applied to all liquid polymers to texture their outer surfaces with a desired porosity is also presented. The proposed process, which is based on two micromolding steps, offers flexibility in terms of tailoring the texture of the final polymer by simply using porous silicon templates with different pore sizes and configurations. The anticipated process was successfully implemented to texture polyethyl hydrosiloxane (PMHS) using porous silicon and polymethyl methacrylate (PMMA) scaffolds.
\end{abstract}

\section{Porous Polymers: Importance and Applications}

For the sake of understanding the motives behind the interest in porous materials in general and particularly in porous polymers, one must first comprehend the inherent significance of the presence of these pores in polymers and how these pores qualify polymers to be excellent candidates for a wide variety of applications nowadays. Accordingly, a number of applications will be mentioned in the following section for the purpose of highlighting why the usage of porous polymers is a promising exercise.

As a beginning, porous polymers are extensively being used for the production of separation membranes [1]. A membrane plays the role of a selective barrier whose structure and function vary with the change of the geometry, cross section structure, and the pore size in the membrane [2].
Consequently, membranes can be classified according to their nature, geometry, and separation regime which in turn are influenced by the characteristics of the pores. Hence, depending on the pore sizes and features, these membranes were found handy in several industrial applications such as microfiltration, ultrafiltration, reverse osmosis, and gas separation. For instance, microfiltration is used for particle removal including sterile filtration. Moreover, reverse osmosis is employed for the production of ultrapure water, including potable water. Meanwhile, ultrafiltration is used for many concentration, fractionation, or purification processes [2]. As for the gas separation, it is utilized for air separation or natural gas purification. Even though membranes can be made from organic (polymeric) and inorganic (ceramic, metal) material [3], polymeric membranes seem to dominate the industrial applications for several reasons. The primary reason is attributed to the fact that various kinds of polymeric 
materials are available commercially. Furthermore, polymers can be used to form different types of selective barriers (porous, nonporous, and charged). Equally important, with the use of polymers, large membrane areas of different shapes can be made with reasonable costs and various versatile fabrication techniques [4].

Another prominent field where porous polymers are starting to be indispensable is the field of tissue engineering [5-8]. Tissue engineering imposes techniques from materials engineering and life sciences for the purpose of replacing, regenerating, maintaining, and/or improving the function of tissue [9]. The approaches that are adopted in tissue engineering for the purpose of fulfilling the previously mentioned aims include planting cells inside the body, supplying the tissue with factors encouraging its growth, and locating cells on or embedding them within matrices. However, the latter approach is the most popular when it comes to tissue engineering as it uses natural or synthetic extracellular substrates as place on which living cells are implanted. This in turn causes the generation of implantable pieces of the organism. Those extracellular substrates are referred to as scaffolds which are defined as porous three-dimensional materials that promote cell growth and proliferation (Figure 1). It is noteworthy to mention that these scaffolds are temporary and are biodegraded when they serve their intended function [6].

In order for scaffolds to meet the requirements of tissue engineering, they should have definite characteristics. The most important of those are being biodegradable as well as biocompatible, having large surface area-to-volume ratios, having high porosities, and possessing proper mechanical strengths. Several biomaterials are found to be biocompatible but not all are biodegradable or bioresorbable. Due to this fact, it was clear that the biomaterials that are suitable to produce bioresorbable scaffolds are either biodegradable polymers or biodegradable ceramics whereas metals and composites are not used in this context since they do not own the required features. However, the inherent brittleness in the ceramics limits their use as a proper material for scaffold fabrication [7]. Having said so, porous polymers seem to be the best candidate for the production of those scaffolds knowing that they best fulfill the various required features to obtain the proper scaffold.

Nonetheless, porous polymers have significantly participated in the advancement of the microelectronics field [10]. This was made possible by the use of a special class of polymers called block copolymers. A block copolymer is a combination of two or more polymers joined end to end [11]. The factor that makes the self-assembling block copolymers an extremely attractive material choice for applications in microelectronics is that they can play the role of sacrificial templates, just like photoresists, and thus can be employed as a powerful tool for patterning integrated circuit elements [10]. The next section presents the different classes of porous polymers. In Section 3, we review the different fabrication processes used to prepare porous polymers. In Section 4, a comparison between these techniques is discussed. Finally, in Section 5 , the proposed generic technique to prepare porous polymers is presented.

\section{Classification of Porous Polymers}

Extensive research has been performed with polymeric materials exhibiting different levels of porosity. Attractiveness of porous polymers is due to their unique properties such as high surface area and other phenomena arising from the spatial dimensions of the material [12]. Porous materials are usually characterized by their size distribution, shape, pore size, extent of interconnectivity, and total amount of porosity. Depending on the application of the porous material to be produced, the dimensions and characteristics of the pores are varied [13]. Pores have been classified, according to the International Union of Pure and Applied Chemistry (IUPAC) definition, as micropores (widths smaller than $2 \mathrm{~nm}$ ), mesopores (widths between 2 and $50 \mathrm{~nm}$ ), and macropores (widths larger than $50 \mathrm{~nm}$ ) [14]. Since "nano" stands for sizes ranging from 1 to $100 \mathrm{~nm}$, all of the above three kinds of porous materials can be designated as nanoporous materials. However, in most of the literature, nanoporous materials refer to mesoporous and/or microporous materials [15].

2.1. Mesoporous Polymers. Members of this novel class of polymers are prepared either by soft-templating approach using organic surfactant molecules as templates (e.g., block copolymer or surfactant micelles) or through a hardtemplating approach using inorganic hard matter as templates (e.g., mesoporous silica or silica nanoparticles) [16].

There are a number of promising applications for mesoporous polymers including their use as catalyst supports, or even metal-free catalysts, in membrane synthesis, separation, and purification. For instance, mesoporous phenolic resins formed by soft templating have been frequently used for the preparation of mesoporous carbons via calcification. On the other hand, mesoporous polymeric carbon nitrides prepared by heating precursors in the presence of silica templates have been shown to be organic semiconductors, which can be employed as metal-free photocatalysts for overall water splitting and other photocatalytic reactions [16].

2.2. Microporous Polymers. In general, polymers possess plentiful conformational and rotational flexibilities which enable them to maximize intermolecular and intramolecular cohesive interactions and packing space efficiently in the solid state. Consequently, the free volume within a polymer, which is the space within the material not occupied by the polymer molecules, can vary remarkably due to certain factors (physical state, molecular structure, recent history, etc.). Hence, if the material owns a sufficiently large free volume, interconnectivity will occur, and microporosity will be significantly presented [14].

It is possible to differentiate between three classes of permanent microporous polymers: hyper-cross-linked polymers (HCPs), polymers of intrinsic microporosity (PIMs), and crystalline covalent organic frameworks (COFs) [16].

In HCPs, a large amount of excess free volume can be obtained by the formation of what is called a hyper-crosslinked network polymer within a solvent-swollen polymer 


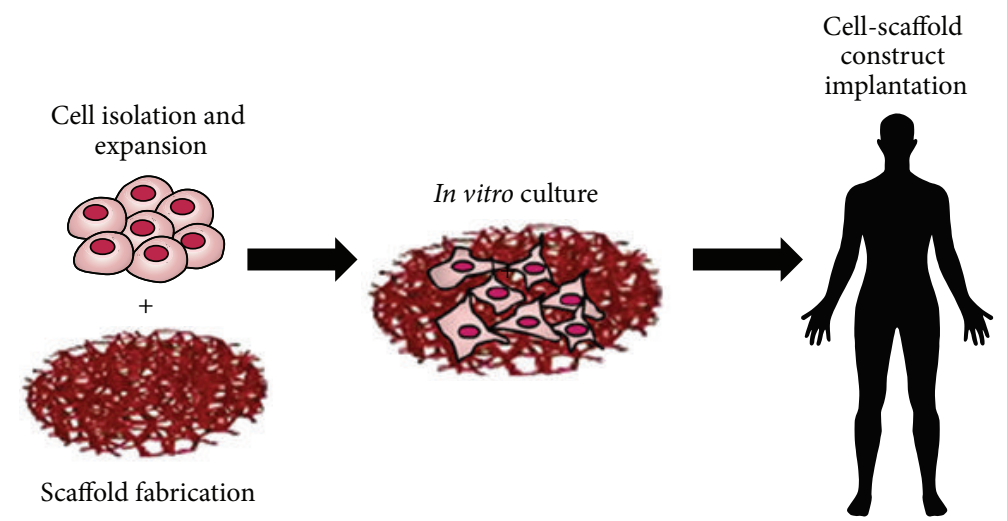

FIGURE 1: Tissue engineering approach that uses scaffolds for the purpose of regeneration of new tissue. The cells are first cultured in vitro under specific conditions on the porous scaffold which, after that, is implanted inside the body. Scaffold is eventually bioresorbed and the space occupied by it is replaced by new tissue that is produced by the cells [7], with permission from Springer.

gel, which, after the removal of the solvent, produces a microporous material. The most investigated class of microporous polymers prepared using this concept is based on hypercross-linked polystyrene resins [14]. The cross-linking of the polymer chain is obtained by using Friedel-Crafts reaction between a cross-linker (typically dichloromethyl hydrocarbons) and the phenyl rings of the polymer [16]. Applications for hyper-cross-linked polymers include adsorption, substrates for chromatography, supports for catalytic metal nanoparticles, and hydrogen and methane storage [14].

As for PIMs (Figure 2), which represent a novel class of polymer based organic microporous materials, the microporosity originates from their interconnected free volume [16]. As a matter of fact, the specific volume of a polymer, $V$, is a combination of the volume occupied by the polymer molecules as well as the free volume of the material. The volume occupied by the polymer molecules can be calculated as the specific van der Waals volume $\left(V_{w}\right)$. Additionally, since even in a perfectly ordered crystals the molecules cannot fill completely the spaces, a part of the volume of the polymer is referred to as the free volume. Accordingly, for a polymer, $V$ increases linearly with temperature. Whatsoever, when the glass transition temperature (the temperature below which the polymer is in a glassy state and above which the polymer is in a rubbery state) is reached, a change of slope takes place in a way that the expansion coefficient is higher in the rubbery state than that in the glassy state. This transition is highly affected by kinetics where it is found that a small increase in the rate of cooling results in a very high increase in the glass transition temperature. Having said so, it was found that if a sample polymer is rapidly cooled and maintained at a temperature slightly below the transition glass temperature the result will be the formation of an excess free volume that is trapped due to rapid cooling and that is slowly lost through physical aging. In other words, if enough excess volume can be imprisoned within an amorphous polymer, a microporous material will be formed. Applications of PMIs involve gas separation membranes, adsorption, heterogeneous catalysis, and hydrogen storage [14].<smiles>CC1(C)Oc2cc3c(cc2O1)C1(C)c2cc4c(cc2Oc2c(C#N)c(C(C)(C)C)c(C#N)c1c2O3)C(C)(C)C41CC(C)(C)C(C)(C)C1</smiles>

(a)

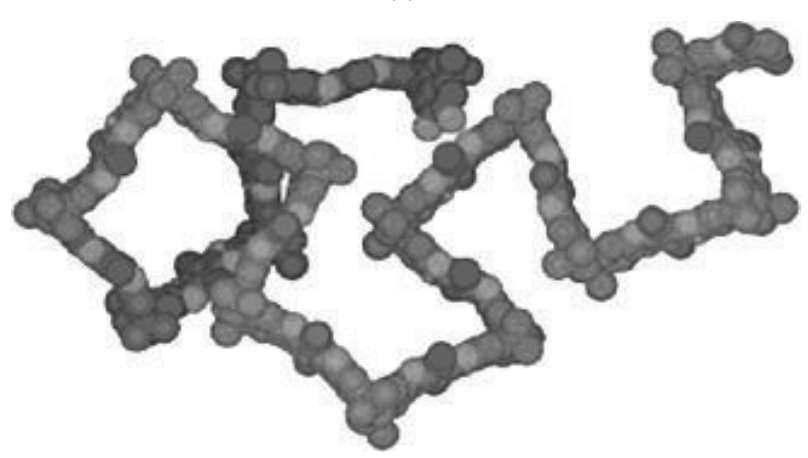

(b)

FIgURE 2: (a) Chemical structure of PMI-I. (b) Molecular model of PMI-I. Reprinted from [16], with permission from Taylor \& Francis.

Yaghi et al. [17] pioneered the work concerning modular metal organic frameworks (MOFs), and their achievement was a turning point that assisted in the development of alternative porous materials in the form of organic frameworks for a wide variety of applications. MOFs are constructed of metal or metal oxide vertices connected by organic link molecules containing functional groups. Regardless of the fact that MOFs have obvious advantages over other porous materials owing to their larger internal surface areas, they exhibit an essential drawback in relation to the presence 


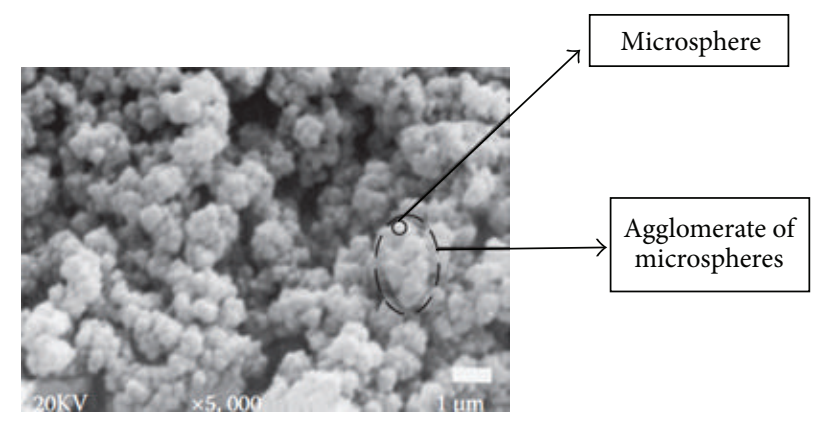

FIGURE 3: SEM image of macroporous poly(N-isopropylacrylamide; PNIPA) network. Reprinted from [23], with permission from Taylor and Francis Group.

of "heavy" metal atoms within their frameworks increasing the weight of their structure. Covalent organic frameworks (COFs) on the other hand rectify this shortcoming since their molecular frameworks consist of light elements (carbon, boron, hydrogen, and oxygen) that reduce the relative weight of the structure [18]. The initially synthesized COF, named COF-1, is obtained from the molecular dehydration of 1, 4benzenediboronic acid (BDBA) [19]. COFs revealed great capabilities for application in the field of hydrogen storage and capture of carbon dioxide [20].

2.3. Macroporous Polymers. As defined by the International Union of Pure and Applied Chemistry (IUPAC), macroporous polymers have pores in the range of $50 \mathrm{~nm}$ to $1 \mu \mathrm{m}$. Macroporous polymers are formed by free-radical crosslinking copolymerization of vinyl-divinyl monomers with the existence of an inert diluent. The design of the pore structure and the resulting macroporosity are dependent on this diluent which acts as a pore forming agent. The diluent could be a solvent, a nonsolvent, or a linear polymer [21]. For instance, during the formation of macroporous polymers by the suspension polymerization of styrene and divinylbenzene (DVB), the diluent is miscible with the monomers but is also a relatively poor solvent for the polymer. As the polymer forms, and due to its poor solubility in the diluent, it precipitates as a separate phase in the polymerizing droplet (phase separation) and the remaining space is filled by the diluent. The result is a bead with high internal surface area permeated with large pores. The final polymer bead can be described as a loose aggregate of tiny submicron-sized particles with the interstitial volume between those particles constituting the porosity [22]. Figure 3 depicts the typical morphology of a macroporous network formed by phase separation polymerization.

Further, depending on the type of method used to form the macroporous polymer, different forms are produced each of which is used in a specialized application. Other than phase separation, different approaches to prepare macroporous materials include freeze-drying, porogenation, microemulsion formation, and gas-blowing technique. For example, macroporous gels are used for isolation of small molecules from the solutions containing suspended materials, monolithic macroporous polymers are employed as chromatographic matrices, macroporous beads are used in chromatographic separation of plasmid DNA, and macroporous polymeric scaffolds are engaged in tissue engineering applications [23].

\section{Fabrication of Porous Polymers}

As the demand for porous polymers with more complex structures and functions has elevated, so has the capability to manufacture such polymers with tunable properties and a diversity of pore characteristics. Accordingly, there is a range of methods that can be utilized to prepare porous polymers. These methods include (1) gas foaming, (2) phase separation (immersion precipitation, chemically induced phase separation, and thermally induced phase separation), (3) small liquid drops templating (emulsion templating, bicontinuous microemulsion templating, and breath figures templating), (4) colloid crystal templating, (5) templating via self-assembled structures (templating via phase separation of block copolymers and using polymer with rod-coil structure), (6) molecular imprinting, and (7) biotemplating using natural biological templates. These techniques of synthesis will be explained below, but it would be beneficial before that to clarify the meaning of a certain expression called "porogen." A porogen is a substance that can be used as a template and then removed to generate pores [14]. Porous polymers are produced as a result of incorporating the porogen into the polymer and then removing it. It is also notable to mention that the porogen may have various forms where it may be, for instance, in the liquid or in the gaseous form. The average pore sizes that have been achieved using the most common of these processes are summarized in Figure 4 .

3.1. Gas Foaming. Polymeric foams can be described as multiphase materials characterized by a solid continuous matrix surrounding a gaseous phase [24]. In other words, polymer foams are porous polymers filled with a very high volume fraction of gas-filled pores [25]. Throughout the years, foams have been incorporated in several applications such as acoustic and thermal insulation, as well as tissue engineering (TE) scaffolds [24].

For the majority of polymer foams, gaseous media are employed for creating the foams. Gas foaming has been commonly utilized to obtain microcellular foams of thermoplastic polymers such as polymethyl methacrylate and polystyrene, but it was not until 1994 that this method was used, by Gualandi, for the production of $\mathrm{PLA}_{50} \mathrm{GA}_{50}$ scaffolds for tissue engineering [7]. Hence, foaming of polymers with gases or supercritical fluids allowed the successful production of microcellular polymers [26].

First, it is worth mentioning a comprehensible definition of a supercritical fluid (SCF). There are two considerable definitions in this field. The first one is defined by Baiker who thought that in order to be given the term supercritical a fluid's temperature must exceed the critical temperature $\left(T_{c}\right)$, 


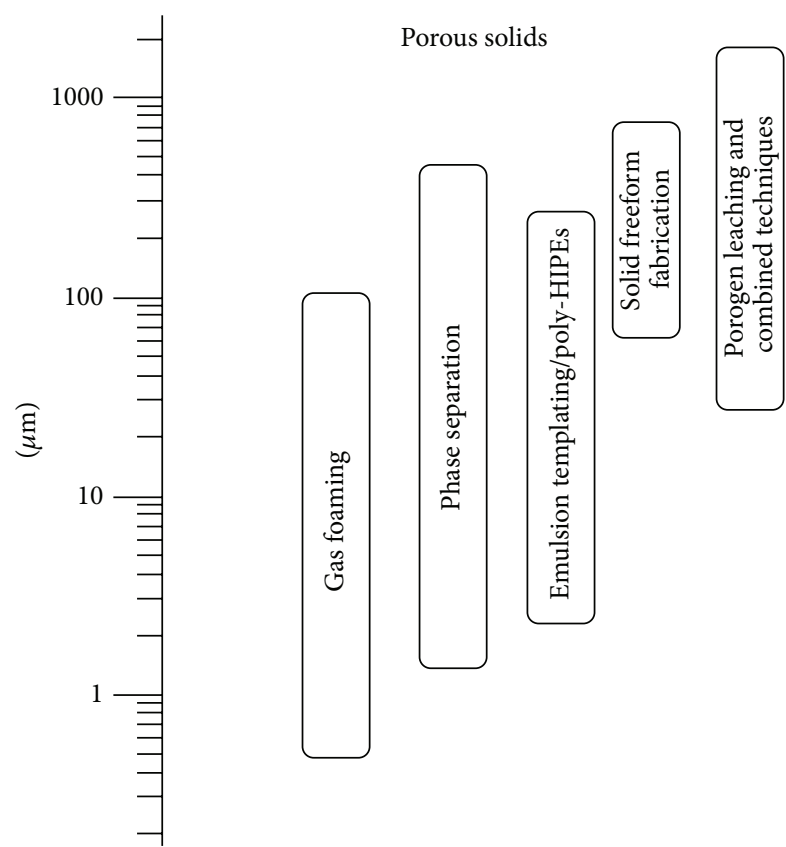

Figure 4: Pore sizes obtained from the most common techniques used for the fabrication of porous solids. Reprinted from [23], with permission from CRC press.

regardless of the pressure [27]. On the other hand, Darr and Poliakoff described a SCF as "any substance, the temperature and pressure of which are higher than their critical values, and which has a density close to or higher than its critical density" [28].

Supercritical carbon dioxide $\left(\mathrm{scCO}_{2}\right)$ is the most common substance employed, which, once turned into the gas phase, acts as a porogen to generate pores within a polymer [7]. Supercritical carbon dioxide is an ideal and clean blowing agent, because $\mathrm{CO}_{2}$ is chemically stable and nontoxic. Additionally, it has a mild critical temperature $\left(31^{\circ} \mathrm{C}\right)$, moderate critical pressure $(7.38 \mathrm{MPa})$, and a relatively high solubility in polymers [29].

This technique is based on three main steps. First, the polymer is saturated with the supercritical fluid at constant temperature and pressure [30]. The sorption of $\mathrm{scCO}_{2}$ into polymers results in their swelling and changes the mechanical and physical properties of the polymers. The most important effect is the reduction of the glass transition temperature $\left(T_{g}\right)$ of glassy polymer subjected to $\mathrm{scCO}_{2}$, often simply called plasticization [31]. Then, the polymer/gas mixture is quenched to the supersaturated state by either reducing the pressure (pressure induced phase separation) or increasing the temperature (thermally induced phase separation). Consequently, the nucleation and growth of gas cells (pores), dispersed throughout the polymer samples, elevate [30]. The apparatus used for the foaming process is portrayed in Figure 5.

In other words, this method includes dissolving $\mathrm{scCO}_{2}$ in a solid polymer at high pressure, which results in generating a low viscosity mixture. Afterwards, depressurization decreases $\mathrm{scCO}_{2}$ solubility in the polymer and leads to the phase transition of $\mathrm{CO}_{2}$ from supercritical to gas. This is followed by $\mathrm{CO}_{2}$ bubble nucleation and nuclei growth, which result in pores within the polymer. Accompanied with that is an increase in the viscosity of the polymer- $\mathrm{SCCO}_{2}$ mixture, enabling the gas to flee from the polymers, leaving behind a solid structure with locked-in pores [31]. The procedure and the resulting porous structure of the polymer foam are illustrated in Figures 6 and 7, respectively.

With the use of $\mathrm{CO}_{2}$ as a porogen, porous polymer microparticles were produced, and it was shown that the pore volume and surface area of the polymer microparticles could be controlled simply by conducting the polymerization under different pressures. However, the limitation of this technique is that it was difficult to control with respect to changes in porosity and pore interconnectivity [32].

3.2. Phase Separation. The second concept of creating pores by the use of a porogen in organic polymers is based on polymer-solvent phase separation processes. This technique involves an initial phase separation followed by a solidification to fix the morphology and finally the removal of the minor separated phase [34].

Phase separation can be triggered during polymerization and cross-linking in several ways. One method includes adding a nonsolvent to a polymer-solvent mixture, and this is termed the "immersion technique." Another method is when polymerization occurs in a monomer/nonsolvent mixture resulting in the diminution of the monomer and the induction of insolubility as a consequence. The last method is known as thermally induced phase separation [25].

3.2.1. Immersion Precipitation. The immersion precipitation process is nowadays widely used in industry to synthesize polymeric membranes [35]. If a polymer-solvent mixture (polymer solution) is immersed into a nonsolvent bath which is nonsolvent to the polymer, precipitation will take place [34]. In other words, this process includes placing a homogenous polymer solution in contact with a nonsolvent. At the interface between those two, an exchange of solvent (which is present inside the polymer solution) and the nonsolvent occurs. Note that the polymer should be soluble in one solvent and insoluble in the other. Meanwhile, the two solvents should be miscible. The polymer solution can be coated on a substrate as a thin film and then immersed in the nonsolvent, or the polymer solution can be cast in the nonsolvent bath [14]. Accordingly, due to this exchange the solution will separate into two phases, a polymer-rich phase and polymerpoor phase (solvent-rich phase), due to the solvent diffusion out of the polymer side to the precipitation bath and due to the nonsolvent diffusion from the precipitation bath to the polymer side [36] as illustrated in Figure 8. An adequate amount of nonsolvent must be present in order to dissolve the polymer solvent that traveled from the polymer on one hand and in order to fill the space that was occupied by this solvent in the polymer-rich phase so that a solidified membrane can be designed. Subsequently, the removal of the nonsolvent that has travelled to the polymer-rich phase will result in the formation of the pores. 


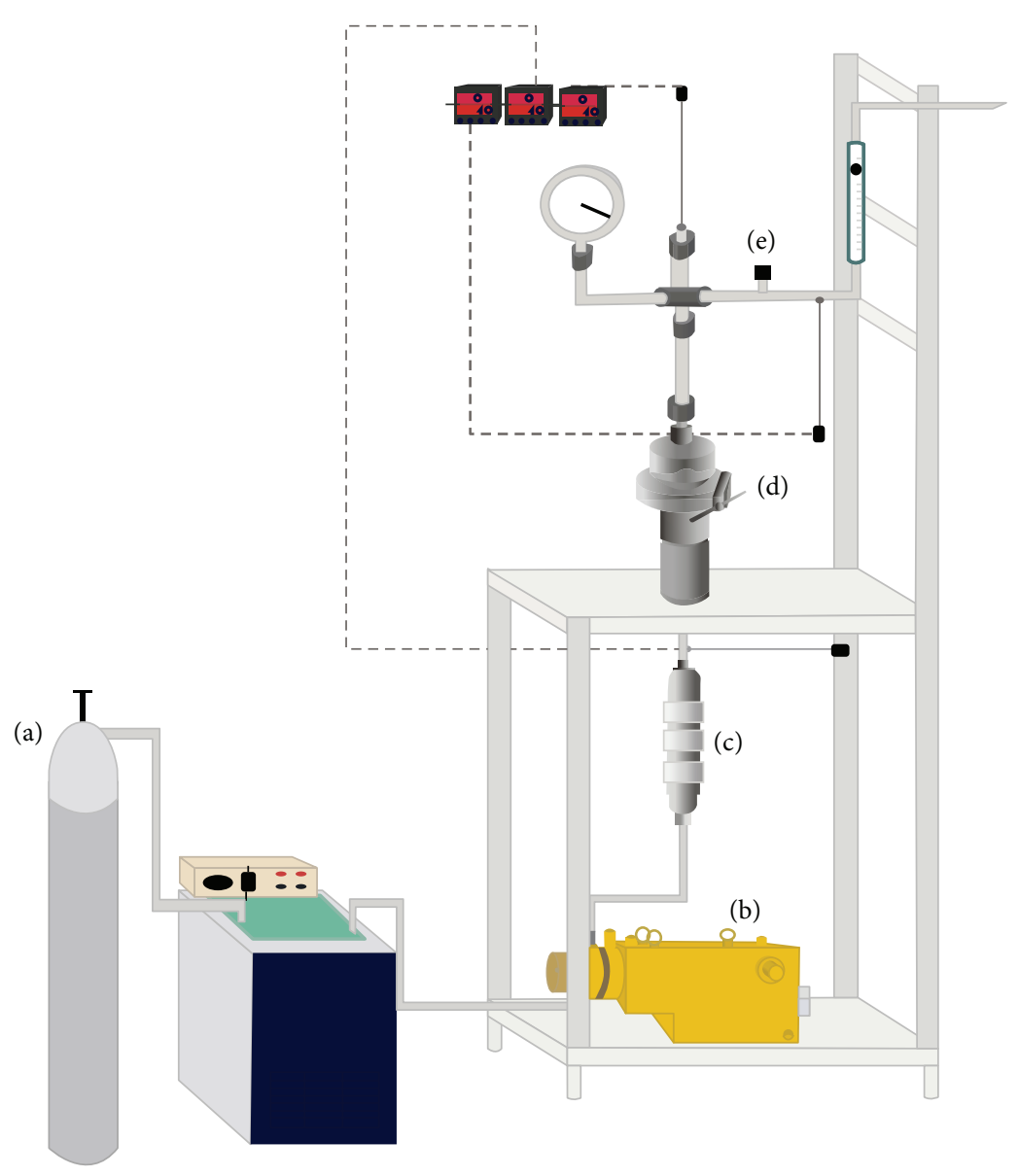

FIGURE 5: Schematic drawing of foaming process apparatus. (a) $\mathrm{CO}_{2}$ tank; (b) high pressure pump; (c) preheater $\left(P_{\max }=350\right.$ bar and $T_{\max }=$ $\left.300^{\circ} \mathrm{C}\right)$; (d) vessel $\left(P_{\max }=350\right.$ bar and $\left.T_{\max }=300^{\circ} \mathrm{C}\right)$; (e) discharge valve. Reprinted from [30], with permission from Elsevier.

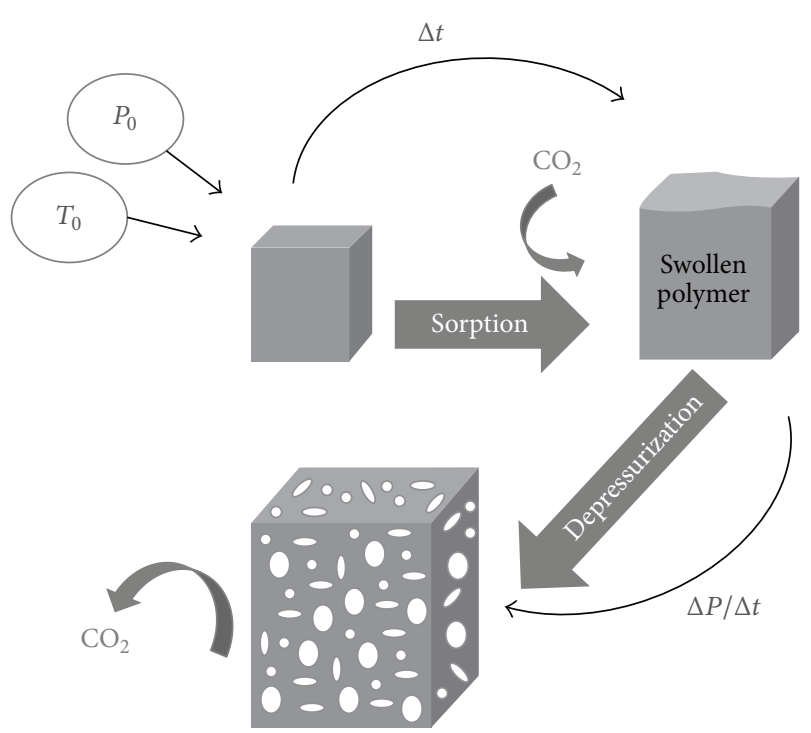

Figure 6: Schematic illustration of the $\mathrm{scCO}_{2}$ foaming process. $P_{0}$ and $T_{0}$ indicate the ambient pressure and temperature, respectively. Reprinted from [14], with permission from John Wiley \& Sons.

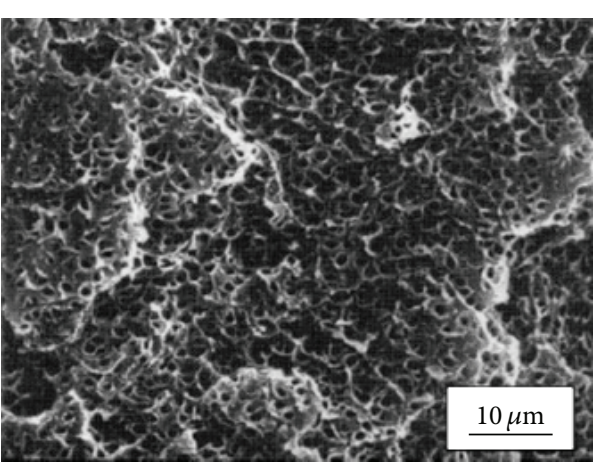

FIGURE 7: SEM micrograph of polystyrene foam. Supercritical $\mathrm{CO}_{2}$ was used as a porogen. Reprinted from [25], with permission from Elsevier.

Due to the diffusion of nonsolvent and solvent in and out of the polymer solution, a ternary system is fashioned. This system consists of the polymer, solvent, and nonsolvent which can be represented by a ternary composition diagram 


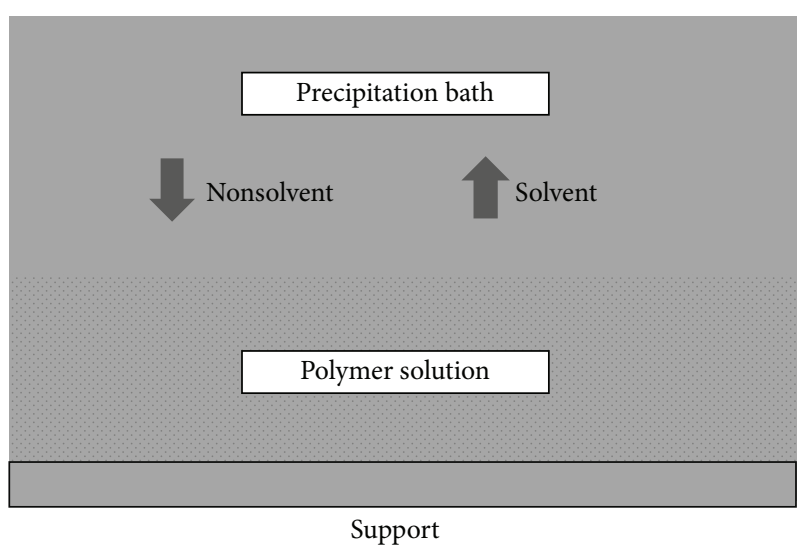

FIGURE 8: Schematic diagram of immersion precipitation technique. Reprinted from [85], with permission from Elsevier.

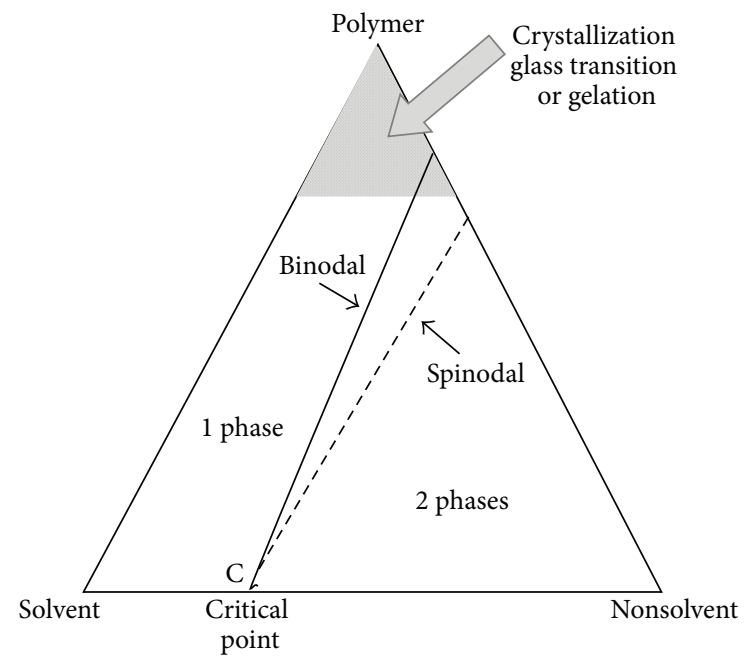

FIgURE 9: Schematic representation of a ternary phase diagram. Reprinted from [36], with permission from Elsevier.

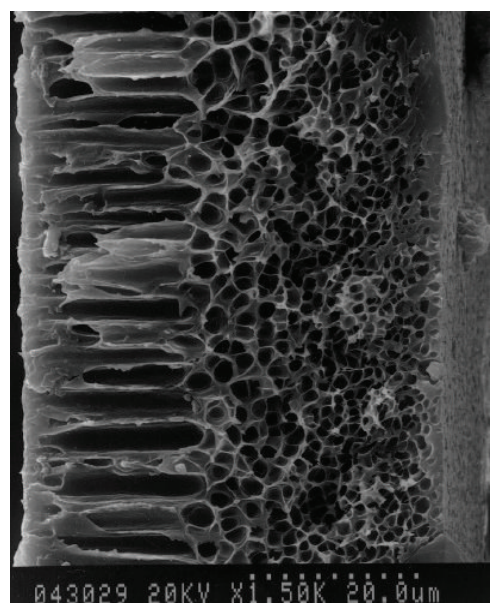

FIGURE 10: SEM photomicrograph showing the cross section of a membrane prepared by immersion precipitation technique. Reprinted from [35], with permission from Elsevier.

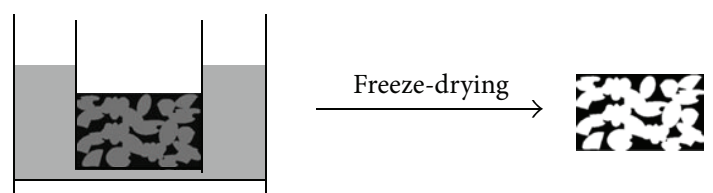

FIGURE 11: Freeze-drying for the preparation of porous materials. (a) A solution is first frozen in a cold bath and (b) the porous material is attained after the removal of the porogen via sublimation. Reprinted from [14], with permission from John Wiley \& Sons.

schematically presented in Figure 9. In this diagram, the binodal curve marks a shift from the single-phase to the twophase region. The spinodal curve, on the other hand, demarcates the metastable and unstable composition regions. As for the shaded area, it represents the composition region where the viscous effects characteristic of the polymer solution may occur. It is up to certain factors, such as the mass transfer rates of the solvent and nonsolvent, to decide which path the polymer solution will follow, the two-phase region or the viscous effect region [36].

When the binodal curve is first attained, liquid-liquid demixing takes place in the polymer solution resulting in two phases, as mentioned previously, one rich in polymer and the other polymer lean. Depending on the physicochemical nature of the system, different phenomena, such as crystallization, gelation, or the crossing of glass transition of the system, may occur. It is the type of phenomenon that dominates during liquid-liquid phase separation that causes the formation of membranes with different morphologies [36].

During membrane formation (Figure 10), the liquidliquid demixing process often leads to a cellular morphology with pores (developed from the polymer-lean phase) being enclosed by a solid polymeric matrix (originated from the polymer-rich phase) [35].

3.2.2. Thermally Induced Phase Separation. In addition to inducing phase separation by bringing a polymer solution into contact with a nonsolvent, thermally induced phase separation (TIPS) is utilized to fabricate porous membranes or microcellular foams [37]. In this method, the two phaseseparated regions (polymer-rich and polymer-poor phases) are obtained when a single homogeneous polymer solution (polymer dissolved in a dilutant), made at a high temperature, is altered by the removal of thermal energy via cooling the solution below the binodal or spinodal line [38].

Subsequent freeze-drying of the liquid-liquid phaseseparated polymer solution produces microcellular structures as a result of solvent removal [37]. Freeze-drying is a process by which a solution is frozen in, or in contact with, a cold bath and then placed in a freeze-dryer to remove the frozen solvent, which acts as a porogen, under vacuum. The porous structure is produced upon the removal of the porogen by sublimation (a direct change from the solid to the gaseous state) under vacuum [14], as illustrated in Figure 11. 

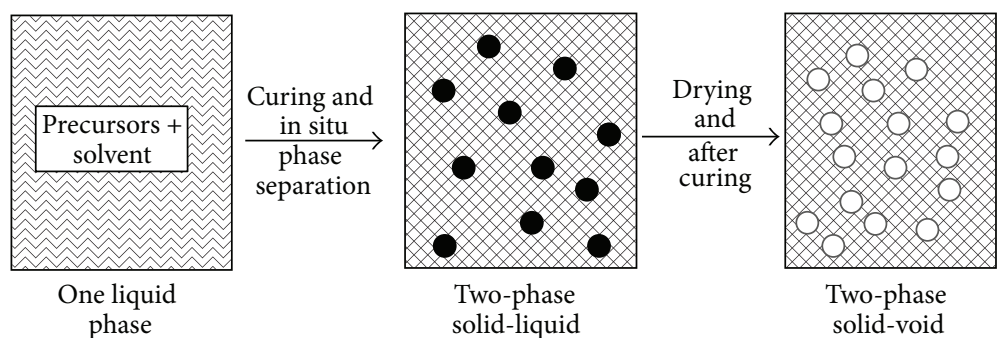

FIGURE 12: Schematic illustration of chemically induced phase separation technique to prepare macroporous thermosets. Reprinted from [40], with permission from Springer.

3.2.3. Chemically Induced Phase Separation. Other techniques of porous polymer synthesis involving controlled phase separation include chemically induced phase separation. In this technique, a two-phase morphology is generated via a phase separation process, resulting from a "chemical quench" [34]. Chemically induced phase separation (CIPS), also known as "polymerization induced phase separation (PIPS)" or "reaction induced phase separation (RIPS)," was first proposed by Kiefer in 1996 [39].

According to Kiefer et al. [40], a change in the free energy resulting in phase separation can also be achieved by continuously changing the molecular weight of the polymer, thus contributing to changes in the entropy. In this methodology, a nonreactive, low molecular weight liquid is used as a solvent for precursor monomers allowing the components to be miscible before the curing process, in order to produce a homogenous mixture. However, when the curing process is initiated, the low molecular weight liquid will become a nonsolvent, and the uniform precursor system undergoes a phase separation into a polymer-rich, continuous phase and a solvent-rich droplet phase. Strictly speaking, the system will be phased into a solid, or a highly cross-linked matrix encapsulating dispersed liquid droplets [40]. The solvent-rich droplets will subsequently grow and merge into each other. After phase separation, the liquid phase should be removed by drying above $T_{g}$, thus leaving a porous structure [34]. This technique was used for the fabrication of macroporous thermosets (Figure 12) [40] and for the synthesis of macroporous epoxy networks (Figure 13) [34].

3.3. Small Liquid Drops Templating (Soft Templating). In this section, the use of soft templates, small liquid drops in specific, as templates for the fabrication of porous materials, is demonstrated. In order for liquid droplets to be used as templates, the materials around the droplets ought to be solidified, and then this should be followed by the removal of the water droplets. The latter is achieved by solvent evaporation, which leads to the production of templated porous materials [41]. In this part, emulsion templating, the use of microemulsion templating for porous structures, and the breath figures pattern are explained.

3.3.1. Emulsion Templating. Emulsion templating is a versatile method for the preparation of highly porous organic

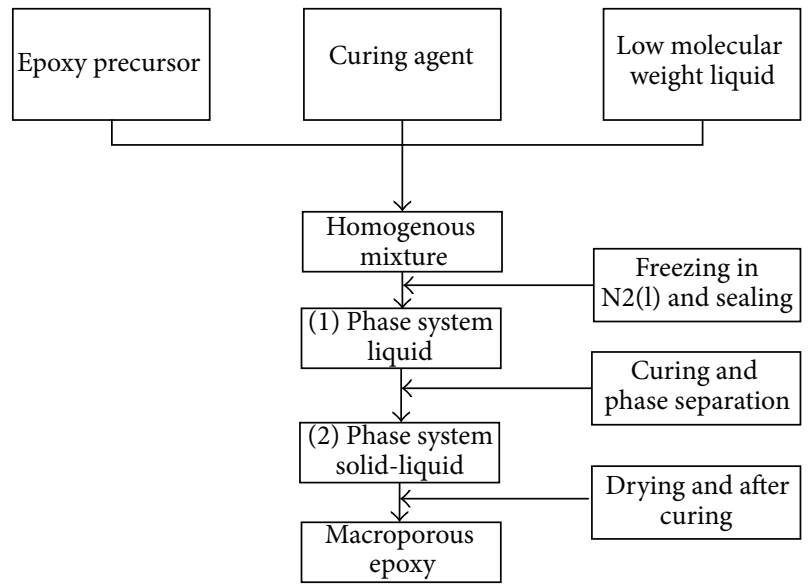

FIGURE 13: Schematic representation of the preparation method of macroporous epoxy via chemically induced phase separation (CIPS). Reprinted from [34], with permission from Elsevier.

polymers, inorganic materials, and inorganic-organic composites [42]. In this strategy, preformed domains of a liquid component are stabilized by a surfactant or a stabilizer in order to prevent macroscopic phase separation [34]. Emulsions are two immiscible solvents mixed together with one phase in the form of droplets dispersed in the other phase [41]. Furthermore, an emulsion is made up mainly of three different parts [34]: the continuous or external phase, the dispersed or inner (aqueous) phase, and the surfactant. For instance, an emulsion can be developed by dispersing water droplets in an oil phase, known as water-in-oil (W/O) emulsion, or dispersing oil droplets in water, known as oilin-water $(\mathrm{O} / \mathrm{W})$ emulsion. In addition, emulsions of $\mathrm{CO}_{2}$-inwater $(\mathrm{C} / \mathrm{W})$ have also been prepared and used for various applications including templating of porous materials [41].

In general, the technique involves forming a high internal phase emulsion (HIPE) in order to produce wide variety of porous polymers generally known as poly-HIPEs. Lissant classified HIPEs as emulsions containing greater than $70 \%$ internal phase volume, although a more precise definition would be those with an internal phase volume above $74.05 \%$ [43].

Polymerized high internal phase emulsions, or polyHIPEs, are materials prepared by polymerizing the continuous phase of an HIPE [44]. For instance, a range of polyHIPE polymers have been prepared by polymerization of the 


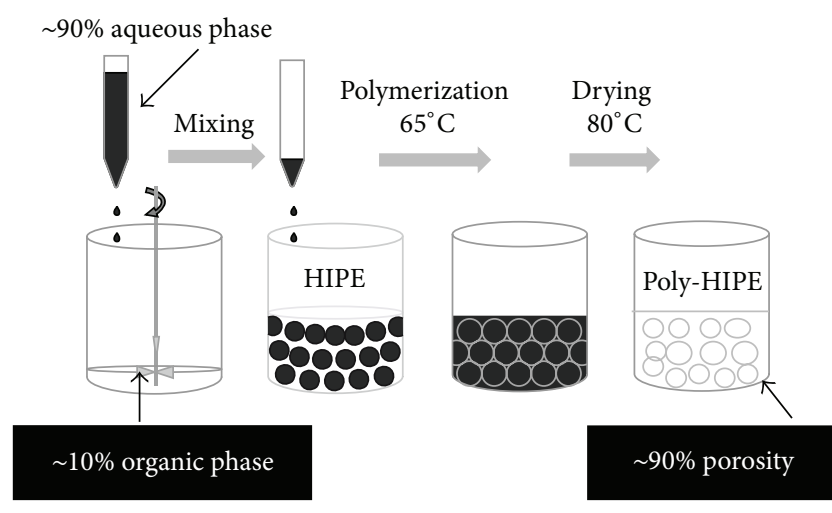

FIGURE 14: Schematic illustration of poly-HIPE formation. Reprinted from [14], with permission from John Wiley \& Sons.

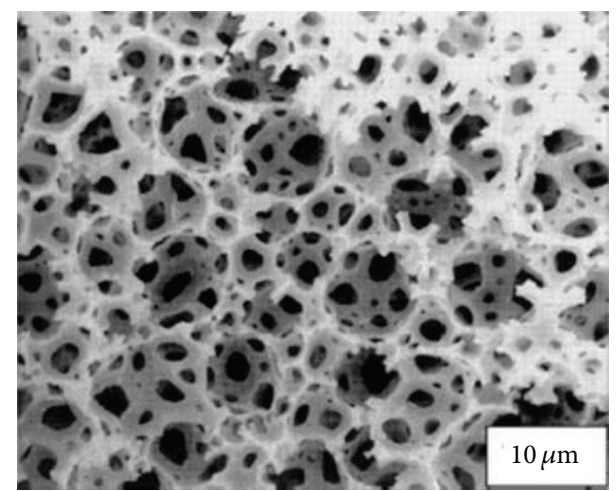

Figure 15: EM micrograph of a poly(styrene-co-DVB) poly-HIPE foam. Reprinted from [25], with permission from Elsevier.

styrene-divinylbenzene continuous oil phase of a number of high internal phase emulsions (HIPEs) [45]. The aqueous internal, or discontinuous, phase constituted approximately $90 \%(\mathrm{vol} / \mathrm{vol})$ in each case and consisted of small droplets of approximately $10 \mu \mathrm{m}$ in diameter. Complete removal of the aqueous phase was achieved after polymerization by exhaustive extraction with hot ethanol, leaving monolithic polyHIPE polymers [25]. Schematic diagrams of experiments performed in order to obtain poly-HIPEs and the resulting porous structure of poly-HIPE upon the extraction of the internal aqueous phase are illustrated in Figures 14 and 15, respectively.

\subsubsection{Bicontinuous Microemulsion Templating. Porous poly-} mers can also be obtained by the polymerization of microemulsions. In the 1950s, Schulman and coworkers [46] added alcohol to surfactant-stabilized oil-in-water $(\mathrm{O} / \mathrm{W})$ emulsions to yield very stable homogenous fluids that were called microemulsions. These microemulsions had an average droplet size of 10-100 nm, much smaller than conventional emulsions. Specifically, they are thermodynamically stable mixtures, typically composed of a nonpolar oil phase, a polar water phase, and a surfactant [47].

It is possible to characterize the constituents of a microemulsion by using a ternary phase diagram, which is usually

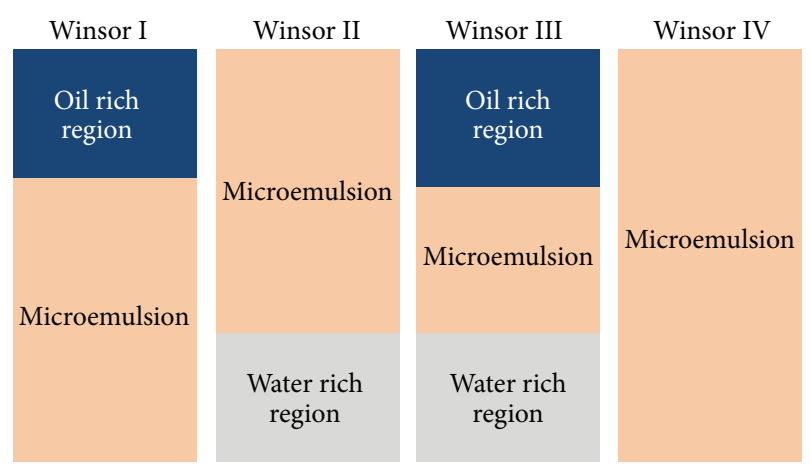

FIGURE 16: Schematic representation on Winsor systems. Taken from [49], with permission from InTech.

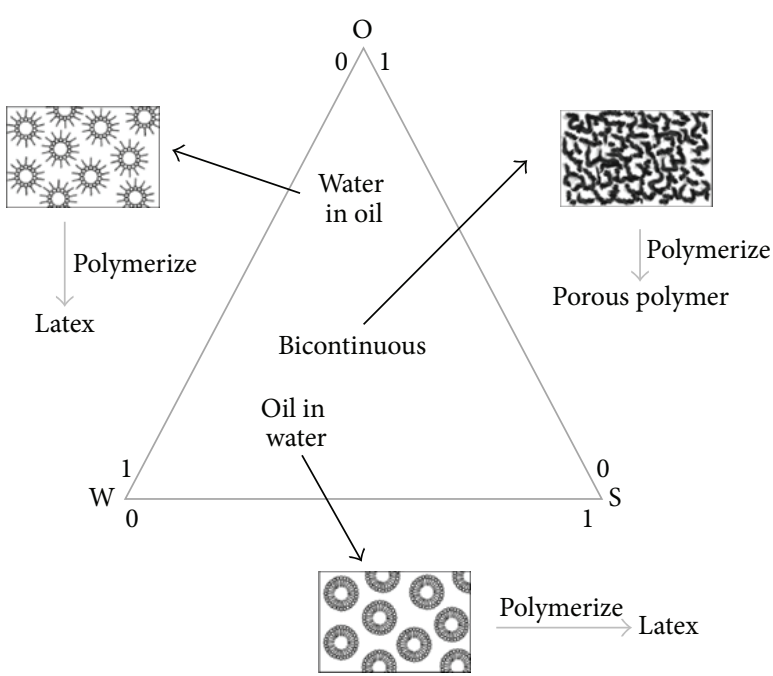

O: oil

W: water

S: surfactant

FIGURE 17: Materials produced from the polymerization of microemulsions. Reprinted from [14], with permission from John Wiley \& Sons.

presented as a triangle with the fractions of water, oil, and surfactant plotted on each side. Different microemulsion structures could rise from different areas of this diagram [14]. Winsor [48] classified these different structures as Winsor I (O/W), Winsor II (W/O), Winsor III (bicontinuous or middle phase microemulsion), and Winsor IV systems (Figure 16). Type I system indicates an $\mathrm{O} / \mathrm{W}$ microemulsion in equilibrium with an oil phase. Inversely, type II system is a W/O microemulsion in equilibrium with an aqueous phase. In type III system, a bicontinuous microemulsion is in equilibrium with both oil and water phases [14]. On the other hand, type IV is a single-phase homogeneous mixture [49].

The polymerization of microemulsions yields the formation of different material. As illustrated in Figure 17, the polymerization of globular $(\mathrm{O} / \mathrm{W}$ or $\mathrm{W} / \mathrm{O})$ microemulsions leads to the production of latex, whereas the polymerization 


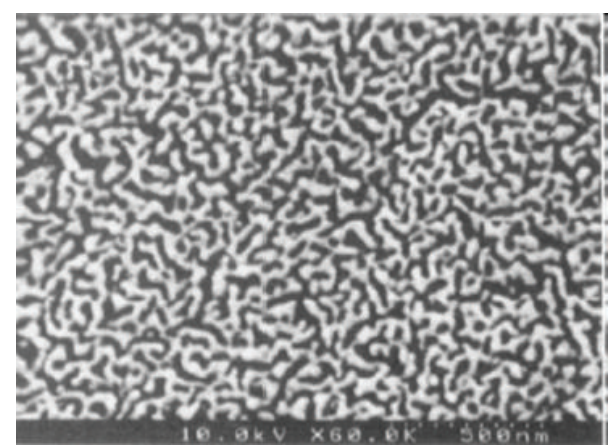

FIGURE 18: SEM of a microemulsion-templated, transparent, porous polymer monolith. Reprinted from [50], with permission from ACS Publications.

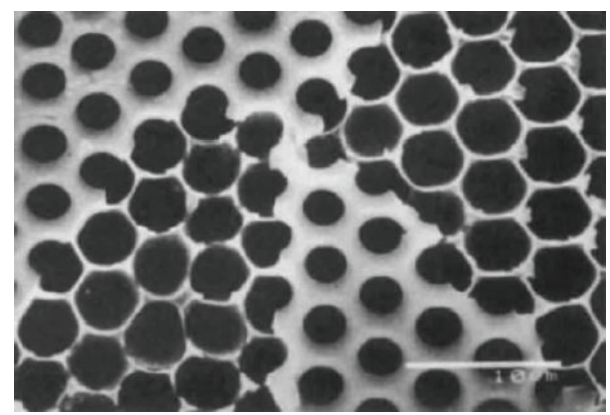

FIGURE 19: Honeycomb film prepared from star polystyrene. Reprinted form [52], with permission from Nature Publishing Group.

of bicontinuous microemulsions leads to the production of porous polymers.

It is noteworthy that porous polymers can be derived from microemulsions containing either polymerizable surfactants or nonpolymerizable surfactants [14]. As an example of polymerizable surfactants, a polymerizable zwitterionic surfactant, acryloyloxy-undecyl-dimethylammonio-acetate (AUDMAA), is used to prepare transparent, porous polymers from methyl methacrylate/ethylene glycol dimethacrylate (MMA/EGDMA) [50]. The bicontinuous structure of the precursor microemulsion is retained, and the micrograph in Figure 18 clearly reveals a channel-like microstructure.

On the other hand, as an example of nonpolymerizable surfactants, it is worthy to note the preparation of transparent microporous solid polymers from a HEMA/MMA/EGDMA/ $\mathrm{W}$ microemulsion system stabilized by a nonpolymerizable surfactant (n-dodecyl trimethylammonium bromide) [51].

3.3.3. Breath Figures Templating. In addition to emulsion templating, the most extensively investigated templating by liquid droplets may be the use of condensed water droplets, widely known as breath figures. In 1994, Widawski et al. demonstrated that either star-shaped polystyrene or poly(styrene- $b$-paraphenylene) forms honeycomb-like regular array of pores in polymer films (Figure 19) when a drop of their solution in carbon disulfide $\left(\mathrm{CS}_{2}\right)$ is exposed to a flow of moist air [52].
In this original work, the evaporation of solutions of a simple coil-like polymer in a volatile solvent, in the presence of moisture with forced airflow across the solution surface, causes the production of hexagonal ordered structures. Consequently, the complete evaporation of the solvent and the water droplets forms the hexagonally packed array of holes on the surface of the polymer, as illustrated in the scheme in Figure 20 [53].

3.4. Colloid Crystal Templating (Hard Templating). In addition to soft colloidal templates (emulsion, microemulsion, and breath figures), hard particles have been also utilized extensively for the production of porous polymers. Among these hard particles, the close packed colloidal crystals have been employed as templates for creating porous materials [54]. Colloidal crystal templating is a hard-templating approach in which porosity is directly modeled by the colloid crystal which is the periodic array of uniform colloidal particles [55]. The procedure involved in this templating method can be summarized in four main steps as shown in Figure 21.

The first step in the process includes the assembly of the particles into a $3 \mathrm{D}$ colloidal crystal matrix, which acts as a template for the formation of the porous structure. A variety of crystallization methods can be used in this content for obtaining the desired crystalline structures. A summary of these methods is represented in Figure 22. These methods include the gravitational sedimentation of the particles that is usually combined with drying of the suspension from above, centrifugation that can accelerate the assembling process and improve the quality of the materials, filtration that accelerates the assembling process and allows easy washing and subsequent infusion with different media, $2 \mathrm{D}$ deposition that is the formation of $2 \mathrm{D}$ crystalline sheets of specific thickness by continuous convective assembling of particles on solid surfaces, in slit filling in which closely packed colloidal crystals are formed when the particle suspensions are filtered through a thin film slit between two solid boundaries, and finally pressing and compaction of particles in the dry state. Latex and silica microspheres are the two major types of particles that are usually used for the colloidal crystal assembly, as they can both be obtained. The second step comprises the infiltration of the interstices or voids between the particles by other particles or fluid of the material that is intended to make pores. This is followed by the third step which is the solidification of the material that penetrated the voids. Solidification could be achieved by a number of different strategies, such as polymerization, solgel hydrolysis of liquid precursor, electrochemical deposition, or precipitation. The final step of the process includes the removal of the colloidal crystal templates from the composite material, either by calcinations or by chemical or physical dissolution, leaving behind a solid skeleton containing 3D ordered array of pores [54].

For instance, porous polyurethane membranes were synthesized by templating latex crystals assembled by injection and accumulation between two solid plates. This was followed by UV-polymerization and the consequent removal of 


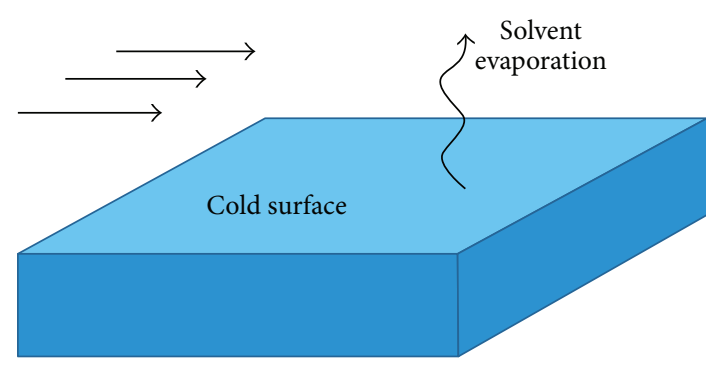

(a) Flow of moist air

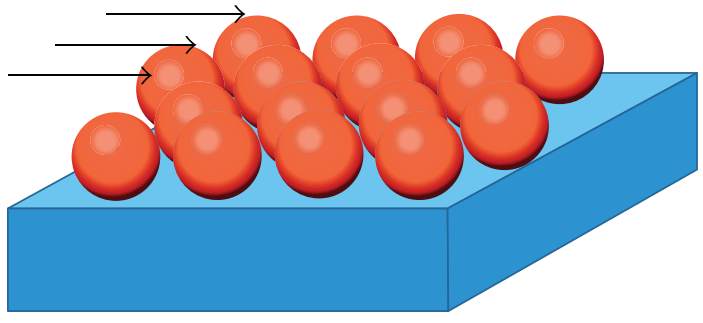

(c) Water droplets from close packed array

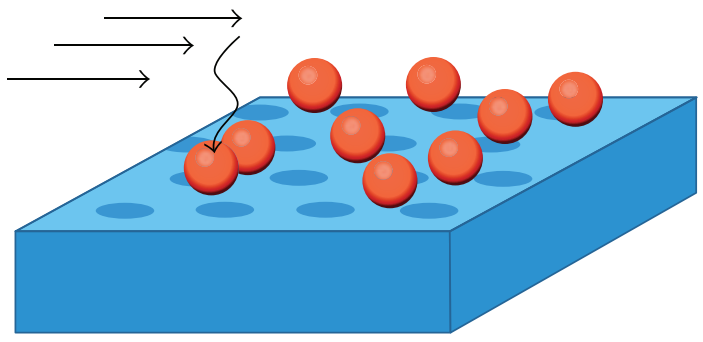

(e) New generation of water droplets

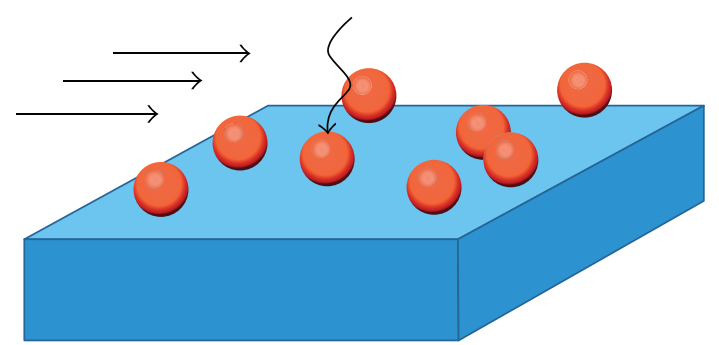

(b) Water condensation (nucleation)

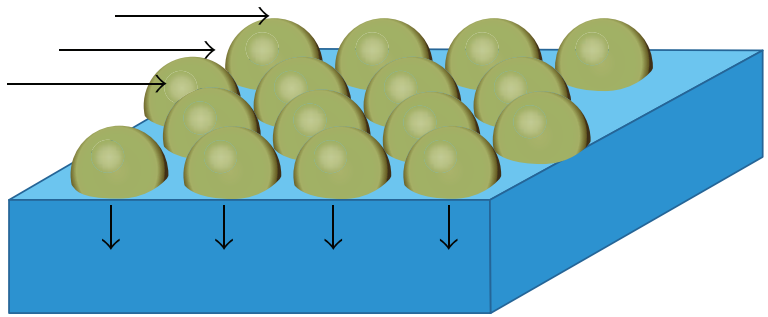

(d) Array cools and sinks into solution

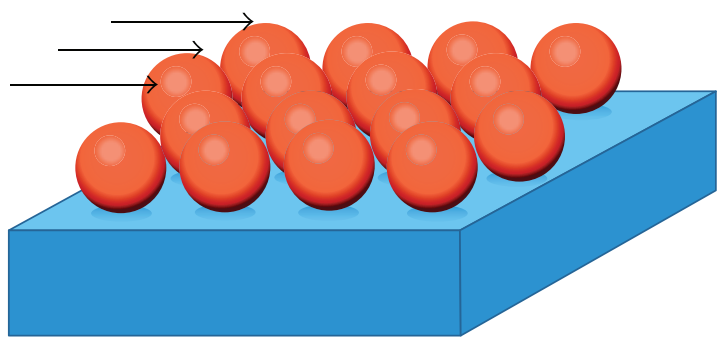

(f) New close packed array templated by underlying layer

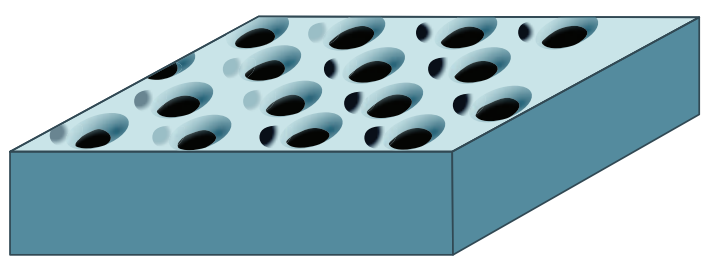

(g) 3D array remains after solvent water evaporates

FIGURE 20: A scheme showing the formation mechanism of ordered porous films via the breath figures templating approach. Reprinted from [53], with permission from Elsevier.

polystyrene lattices by selective extraction with toluene [56]. In a similar procedure, colloidal crystals of monodisperse silica particles were employed as templates and removed by hydrofluoric acid after UV-polymerization of polyurethanes and poly(acrylate-methacrylate). These porous membranes found applications in filtration, separation, tissue engineering, and fabricating diffractive sensors and photonic band gap (PBG) materials due to their three-dimensional periodic structures [57].

\subsection{Templating via Self-Assembled Structures}

3.5.1. Templating via Microphase Separation of Copolymer. Phase separation in block copolymer solutions has been an interesting field in the recent years, for its contribution in fabricating porous periodic patterns on a nanoscale. A block copolymer is a heterogeneous polymer that is covalently linked with two or more different types of chemically distinct monomer, and the similar repeating monomer units occur together in blocks of long sequences [53]. Under certain conditions, a net repulsion between the incompatible heterogeneous polymer blocks induces their local segregation or "microphase separation" [58]. However, as a result of the chemical (covalent) linkage holding the blocks together, additional macroscopic phase separation is prohibited. Consequently, the block copolymer systems spontaneously selforganize into different domains that exhibit ordered morphologies at equilibrium [53]. Nonetheless, one of the blocks, termed the "sacrificial block," typically needs to be removed (etched) to generate a porous structure [14]. Various etching techniques and block copolymers employed for the production of porous structures are summarized in Table 1. 


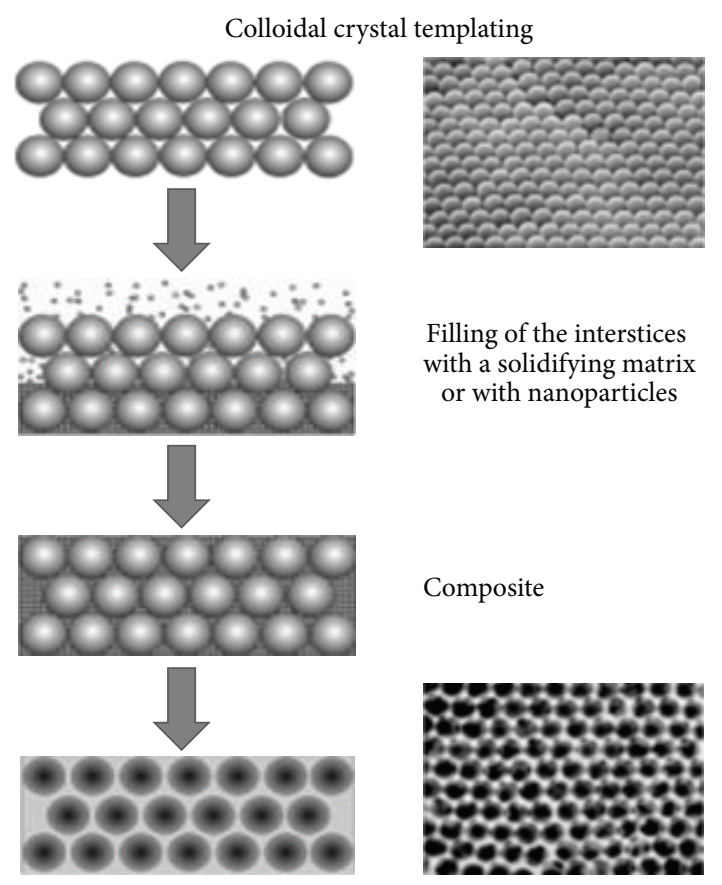

Structured porous replica

FIGURE 21: General process for replicating the structure of colloidal crystals into porous materials. Reprinted from [54], with permission from Elsevier.

TABLE 1: Typical materials and etching techniques for preparation of nanoporous materials from block copolymers. Reprinted from [14], with permission from John Wiley \& Sons.

\begin{tabular}{|c|c|c|}
\hline Polymers & $\begin{array}{c}\text { Sacrificial } \\
\text { block }\end{array}$ & Etching conditions \\
\hline PS-PMMA & PMMA & $\begin{array}{l}\text { Deep UV exposure followed by } \\
\text { acetic acid rinsing }\end{array}$ \\
\hline PS-PI & PI & \\
\hline PVP-PI & PI & Ozonolysis \\
\hline PS-PBD & PBD & \\
\hline $\begin{array}{l}\text { PS-PLA } \\
\text { PCHE-PLA }\end{array}$ & PLA & $\begin{array}{l}0.5 \mathrm{M} \mathrm{NaOH} \text { in } 40: 60(\mathrm{v} / \mathrm{v}) \\
\text { methanol/water mixture }\left(65^{\circ} \mathrm{C} \text {, }\right. \\
5-10 \text { days })\end{array}$ \\
\hline $\begin{array}{l}\text { PS-PLLA } \\
\text { PS-PEO }\end{array}$ & $\begin{array}{l}\text { PLLA } \\
\text { PEO }\end{array}$ & $57 \mathrm{wt} \% \mathrm{HI}_{(\mathrm{aq})}\left(65^{\circ} \mathrm{C}, 5\right.$ days $)$ \\
\hline $\begin{array}{l}\text { PI-PDMS } \\
\text { PB-PDMS }\end{array}$ & PDMS & 1.0 M TBAF in THF (RF, 36-48 h) \\
\hline $\begin{array}{l}\text { PS-PDMS } \\
\text { PtBA-PCEMA }\end{array}$ & $a$ & $\begin{array}{l}\text { Anhydrous } \mathrm{HF}\left(0^{\circ} \mathrm{C}, 2 \mathrm{~h}\right) \\
0.05 \mathrm{M} \text { TMSI in } \mathrm{CH}_{2} \mathrm{Cl}_{2}(\mathrm{RT}, \\
\text { 2-14 days) followed by } 5: 95(\mathrm{v} / \mathrm{v}) \\
\text { water/methanol (RT, } 2 \text { days) }\end{array}$ \\
\hline PE-PS & PS & Fuming nitric acid (RT, $30 \mathrm{~min}$ ) \\
\hline P(imide)-PPG & PPG & Heat to $240^{\circ} \mathrm{C}$ under vacuum \\
\hline
\end{tabular}

Taking the example of a diblock copolymer, the system will self-assemble into two different domains following the microphase separation. In a given diblock copolymer system, the relative chain lengths of the blocks determine the resulting morphology. The polymer which possesses a larger block length will constitute the matrix domain, whereas that of the smaller block length will assemble the nanometer or micrometer scale domain [53]. The microdomain size of block copolymers is basically determined by the total molecular weight with resulting morphologies (i.e., microdomain patterns) expected to be uniform-sized spheres, cylinders, and lamellae, as well as complex bicontinuous nanostructures [59] as illustrated in Figure 23. Eventually, the porous structure will be obtained as a result of removing or etching the internal nano/microdomains by one of the various etching techniques mentioned in the previous table.

Porous materials derived from block copolymers have several features that make them useful in applications nanopatterning [60] and in nanoporous membranes [6163]. Regarding nanopatterning, for instance, Park et al. [60] demonstrated a periodic array with a density $~ 1011$ holes $/ \mathrm{cm}^{2}$ by pattern transfer from spherical microdomains in PS- (polystyrene-) block-PB (-polybutadiene) or PS-blockPI (-polyisoprene) to the underlying semiconductor (silicon nitride) substrate by fluorine-based reactive ion etching (RIE) techniques, as shown in Figure 24. The use of ozonated copolymer film produces holes in silicon nitride, whereas the use of osmium-stained copolymer film produces dots in silicon nitride. Meanwhile, an example of the use of block copolymers in the synthesis of nanoporous membranes can be demonstrated by shedding light on the efforts of Yang et al. [63], who prepared a nanoporous membrane using a PS-block-PMMA thin film with vertically aligned cylindrical microdomains, as schematized in Figure 25.

3.5.2. Templating Using Polymer with Rod-Coil Structure. Jenekhe and Chen [64] used a self-assembled method utilizing rod-coil block copolymers to produce honeycomb structures. When the rod-coil diblock copolymers were dissolved in a selective solvent for the coil-like polymer, they had the ability to self-organize into hollow spherical micelles having diameters of a few micrometers. The long range, close packing, and self-ordering of the micelles subsequently produced highly iridescent periodic microporous materials. The rod-coil diblock copolymer that was used is poly(phenylquinoline)-block-polystyrene $\left(\mathrm{PPQ}_{m} \mathrm{PS}_{n}\right.$, where $m$ and $n$ are the number of repeat units of the respective blocks). As illustrated in Figure 26, after dissolving $\mathrm{PPQ}_{m} \mathrm{PS}_{n}$ in a selective solvent for PS-block, carbon disulfide $\left(\mathrm{CS}_{2}\right)$, micelles were formed, and then the micelle containing solution was cast on films to yield multilayers of hexagonally ordered arrays of spherical holes.

3.6. Molecular Imprinting. Molecular imprinting, a means by which highly selective recognition sites can be generated in a synthetic polymer, was first formalized as a practical methodology by Wulff and coworkers in 1972 [65]. More recently in 1995, Steinke et al. identified molecular imprinting as a technique for template synthesis of polymers with pores structured on a molecular scale [66]. Molecular imprinting mainly revolves around the assembly of a cross-linked polymer matrix with templating moieties. As a consequence of removing the templates, cavities or recognition sites are established, which are complementary, both in terms of shape and functionality, to the original template present in the sites 


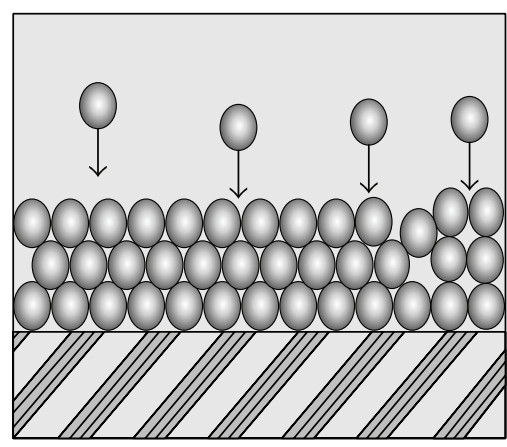

Sedimentation

(a)

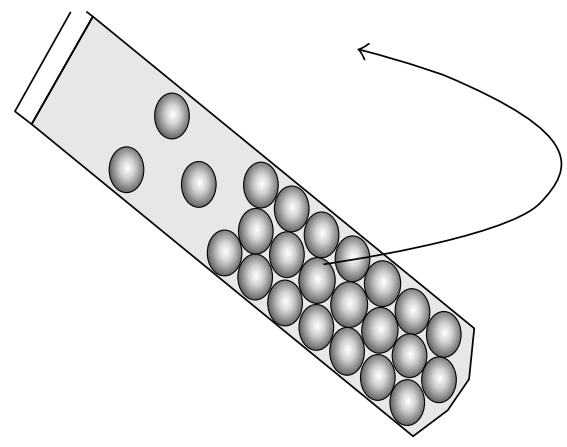

Centrifugation

(b)

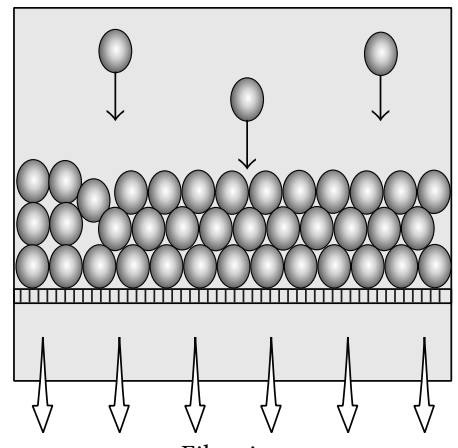

(c)

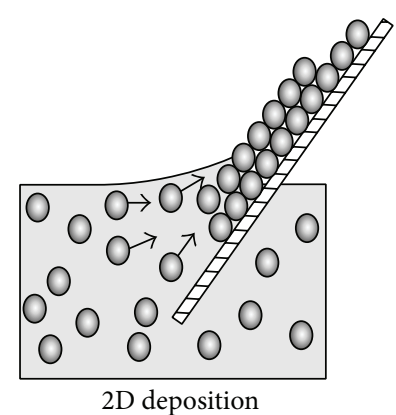

(d)

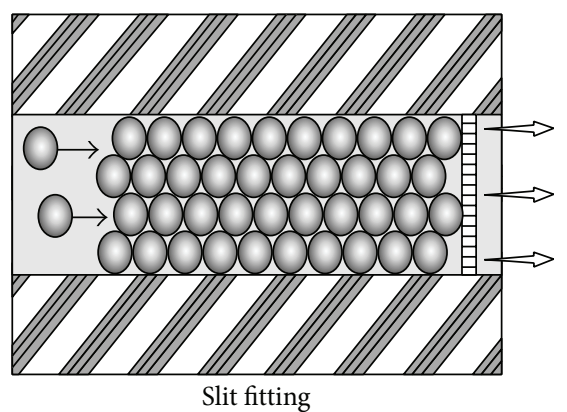

(e)

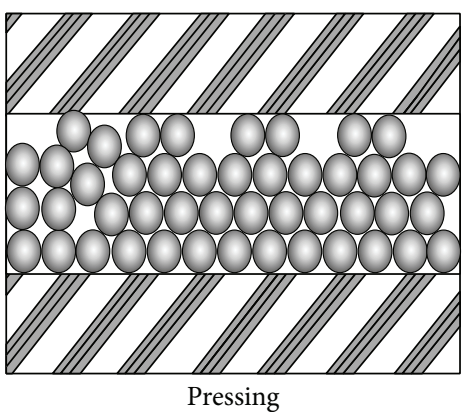

(f)

FIGURE 22: Various methods used for assembling colloidal crystal template. Reprinted from [54], with permission from Elsevier.

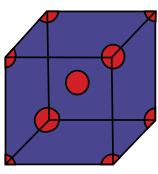

S

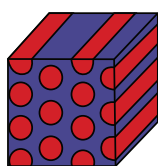

C

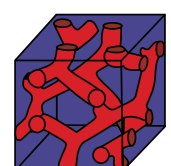

G

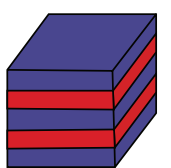

$\mathrm{L}$

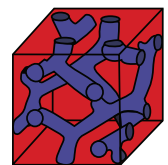

$\mathrm{G}^{\prime}$

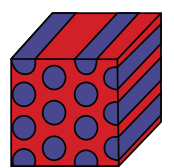

$\mathrm{C}^{\prime}$

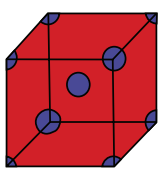

$\mathrm{S}^{\prime}$

$f_{A}$

FIGURE 23: Mean-field prediction of the thermodynamic equilibrium phase structures for conformationally symmetric diblock melts. Phases are labeled as L (lamellar), C (hexagonal cylinders), G (bicontinuous cubic), and S (body-centered cubic spheres). $f_{A}$ is the volume fraction. Reprinted from [86], with permission from Elsevier.

(Figure 27) [65]. In other words, this synthesis technique is usually executed by copolymerization of functional and cross-linking monomers in the presence of a molecular template (imprint molecule). The functional monomer and template molecules will then have to interact either by covalent or by noncovalent bonding. This is followed by the removal of the molecule template after polymerization. The removal is done via extraction or chemical cleavage, leaving behind molecular imprinted cavities which are compatible with the imprint molecules [25]. Applications for molecularly imprinted polymers include affinity separation, antibody binding mimics, enzyme mimics, and biomimetic sensors [67].

3.7. Biotemplating: Using Natural Biological Templates. Biological structures with complex morphologies and various types have been vastly used as sophisticated templates to prepare porous materials with tailored structures. Some of the examples include bacterial threads [68], echinoid skeletal plates [69], eggshell membranes [70], insect wings [71], pollen grains [72], plant leaves [73], wood [74], and natural cellulose matrices such as filter paper, cloth, and cotton [75]. In addition, crystalline networks with hierarchical structure were fabricated by carbothermal reduction of titania-coated cellulose paper [76].

The scheme in Figure 28 depicts how a bacterial (Bacillus subtilis) superstructure consisting of a thread of coaligned multicellular filaments arranged in a hexagonal packing can be used as a biotemplate to produce ordered macroporous fibers of either amorphous silica or ordered mesoporous silica [68]. In route I, the bacterial threads were infiltrated by silica sol, whereas in route II they were infiltrated by a Mobile 


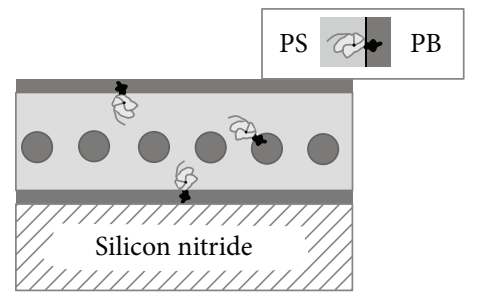

(a)
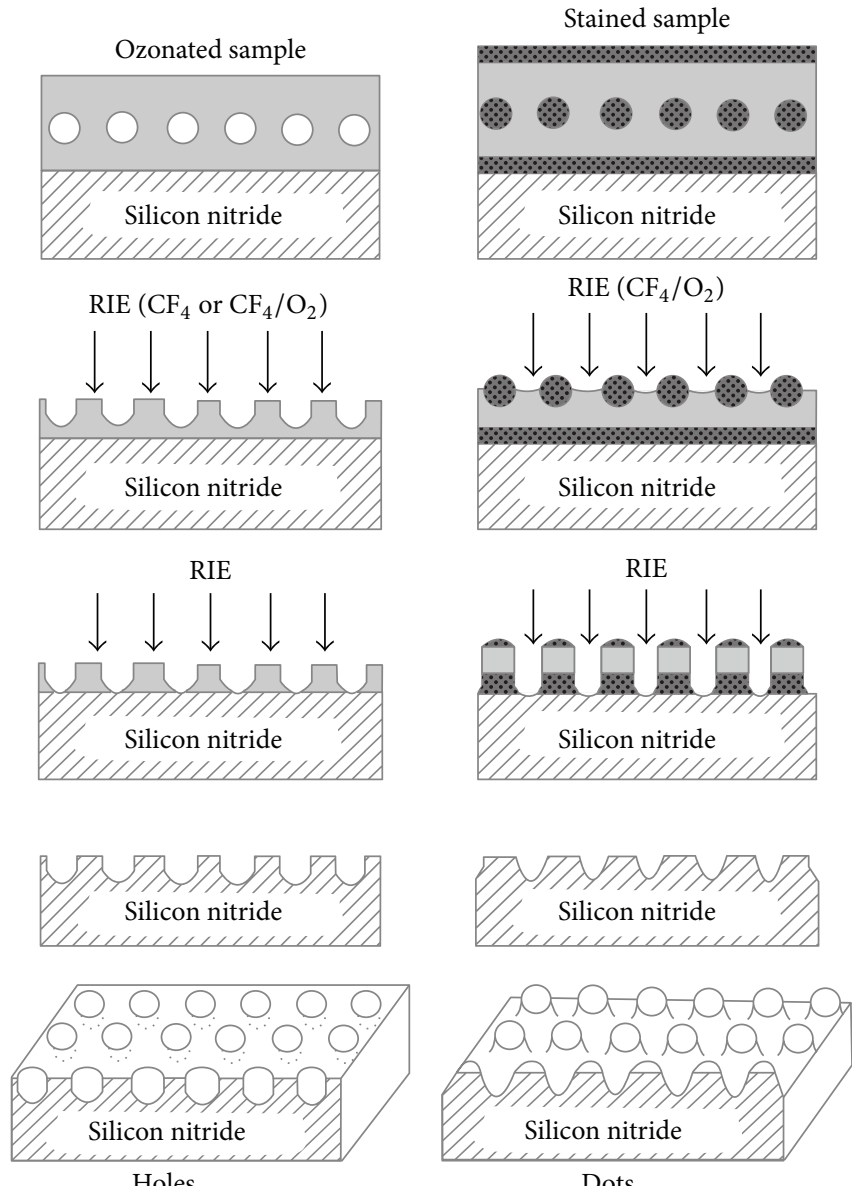

(b)

(c)

FIGURE 24: (a) Schematic cross-sectional view of a nanolithography template consisting of a uniform monolayer of PB spherical microdomains on silicon nitride. PB wets the air and substrate interfaces. (b) Schematic of the processing flow when an ozonated copolymer film is used, which produces holes in silicon nitride. (c) Schematic of the processing flow when an osmium-stained copolymer film is used, which produces dots in silicon nitride. Reprinted from [60], with permission from American Association for the Advancement of Science.

Crystalline Material (MCM) phase. As a result, the cell wall and interfilament spaces were mineralized. The final porous structure was obtained by the removal of the biotemplates (bacteria) via subsequent heat treatment $\left(600^{\circ} \mathrm{C}\right)$.

\section{Comparison between Most Common Fabrication Techniques}

The following section will include a comparison between the main types of fabrication techniques and listing of the advantages and disadvantages of those methods (Table 2). As a beginning regarding the gas foaming technique, it differs from other techniques that require the use of organic solvents and high temperatures whose residues that remain after completion of process can damage cells and nearby tissues. Instead, in this method polymers are pressurized at high pressures with gas foaming agents, such as $\mathrm{CO}_{2}$ and nitrogen, water, or fluoroform, until the polymers are saturated. This results in nucleation and growth of gas bubbles with sizes ranging between 100 and $500 \mu \mathrm{m}$ in the polymer. The porosity and porous structure of the scaffolds depend upon the amount of gas dissolved in the polymer. Although it has 


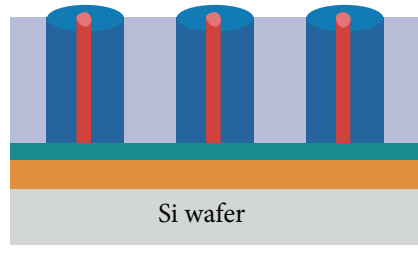

(a)

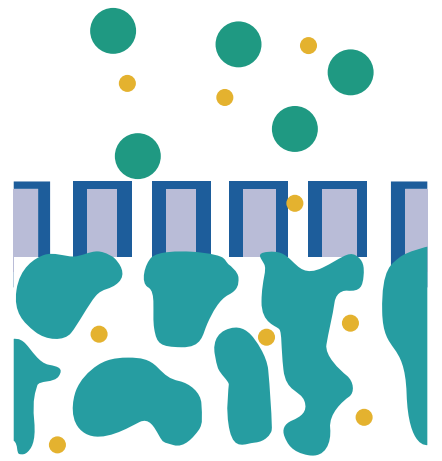

(d)

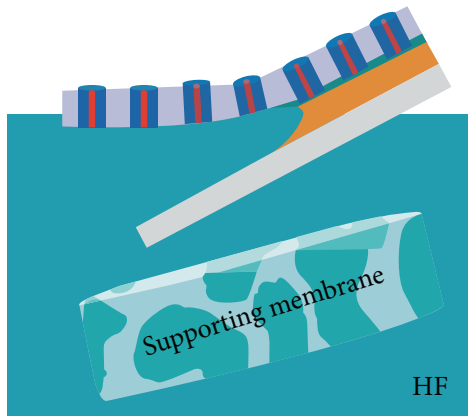

(b)

Acetic acid
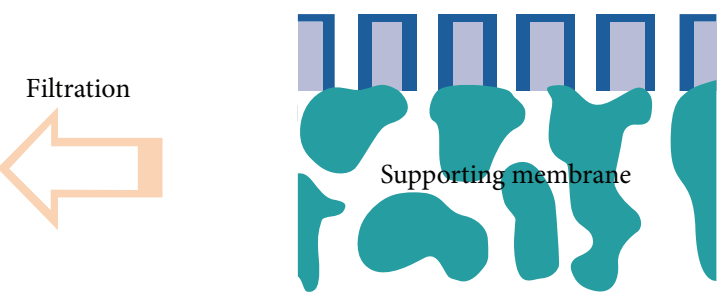

(c)

- Neutral brush

- PMMA block

FIGURE 25: Schematic depiction of the procedure for the fabrication of nanoporous membrane consisting of block copolymer thin film and supporting. Reprinted from [63], with permission from John Wiley \& Sons, Inc.

TABLE 2: Advantages and disadvantages of main types of fabrication techniques [33].

\begin{tabular}{lll}
\hline Fabrication method & Advantages & Disadvantages \\
\hline Solvent casting/particulate leaching & $\begin{array}{l}\text { Control over porosity, pore size, and } \\
\text { crystallinity }\end{array}$ & $\begin{array}{l}\text { Limited mechanical property, residual } \\
\text { solvents, and porogen material } \\
\text { Porogen leaching }\end{array}$ \\
Controlled over porosity and pore geometry \\
Gas foaming & $\begin{array}{l}\text { Free of harsh organic solvents, control over } \\
\text { porosity and pore size }\end{array}$ & $\begin{array}{l}\text { Limited mechanical property, inadequate } \\
\text { pore interconnectivity }\end{array}$ \\
Phase separation & $\begin{array}{l}\text { No decrease in the activity of the molecule } \\
\text { High temperature and separate leaching step } \\
\text { not required }\end{array}$ & Difficult to control precisely morphology \\
Freeze-drying & Small pore size and long processing time
\end{tabular}



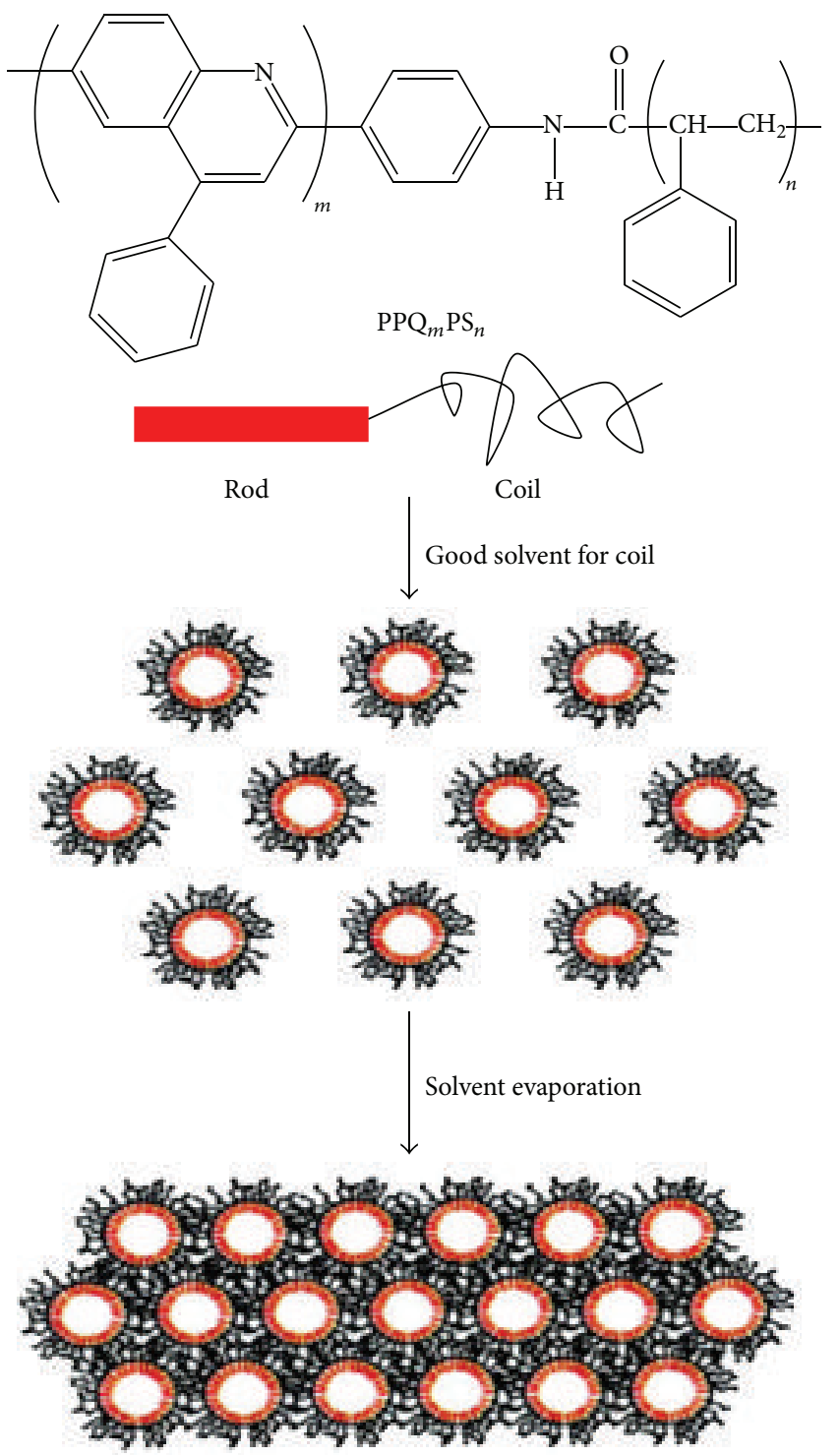

FIGURE 26: Rod-coil block copolymer for microporous materials. Solution-cast micellar films consist of multilayers of hexagonally ordered arrays of spherical holes. Reprinted from [64], with permission from American Association for the Advancement of Science.

the advantage of being an organic solvent-free method, the major drawback is that the process may yield a structure with largely unconnected pores and a nonporous external surface. On the other hand, the phase separation technique is based on a temperature change that splits up the polymeric solution in two phases, one having low polymer concentration (polymerlean phase) and the other having the high polymer concentration (polymer-rich phase). A liquid-liquid phase is separated and quenched by diminishing the temperature. This results in forming a two-phase solid. The solvent is then removed by extraction, evaporation, and sublimation in order to give rise to the porous structure. The structure of the resulting pores is controlled by varying process parameters such as polymer concentration, quenching temperature, and quenching rate. The advantages of phase separation technique are that it can easily combine with other fabrication technologies to design three-dimensional structures with control pore morphology. Meanwhile, the other fabrication techniques mentioned in this review are based on the concept of porogen leaching. This method is the most common method for producing porous structures of controlled porosities. These porogens act as place holder for pore and interconnection of the pores. The main advantages of fabrication techniques including porogens are simplicity, versatility, and ease of controlling the pore size and geometry $[33,77]$.

\section{Fabrication of Porous Polymer Using Porous Silicon Scaffolds}

Figure 29 illustrates our generic fabrication process that can be applied to all types of liquid polymers in order to texture their surfaces with a desired porosity for a specific application. The process consists of two micromolding-based steps. The first step, which determines the final porosity of the polymer, starts with a piece of silicon substrate, which will be spin-coated with a layer of photoresist and photolithographically patterned to expose a specific and well determined window in the silicon wafer piece, as depicted in Figure 29(b). The exposed silicon is made porous using xenon difluoride etching technique [78], as illustrated in Figure 29(c). Polymethyl methacrylate (PMMA) is then poured on the silicon surface (Figure 29(e)). Once the PMMA is cured, it is peeled off, as represented in Figure 29(f). PMMA now represents the second molds for the final polymer. Polymethyl hydrosiloxane (PMHS) is then poured on the PMMA surface, as shown in Figure 29(g), and peeled off to form the final PMHS polymer, which is identical to the porous silicon template.

5.1. Preparation of Porous Silicon. Porous silicon (PS) is a form of the chemical element silicon, which introduces nanoporous holes in its structure. An essential requirement of the fabrication of porous silicon for the use in different applications is the ability to vary the size and configuration of the pores by choosing the appropriate fabrication parameters. Large numbers of potential binding sites are provided by the silicon surface due to its large surface area which increases the interests in porous silicon for chemical and biological sensing applications. Porous silicon is prepared through galvanostatic [79], gas [80], pulsed anodic [81], chemical [82], or photochemical [83] etching procedures and through strain etching [84].

Here, $\mathrm{XeF}_{2}$ dry etching is utilized to create porous silicon surfaces on single crystalline silicon wafers. 3-inch diameter, $381 \pm 20 \mu \mathrm{m}$ thick $<100>$ boron-doped $(5-10 \mathrm{ohm} \mathrm{cm})$ silicon wafers are used. The wafer is cut into $2 \times 2 \mathrm{~cm}^{2}$ that are then loaded in the $\mathrm{XeF}_{2}$ etching chamber. The $\mathrm{XeF}_{2}$ etching process does not depend on the silicon crystal orientation or its dopant content.

The fabrication process is achieved in a sequence of steps. First, undissociated gaseous $\mathrm{XeF}_{2}$ is adsorbed onto the exposed areas of bulk silicon. The adsorbed gas is then dissociated into xenon and fluorine, after which the fluorine 


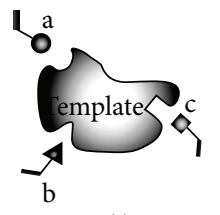

(i)
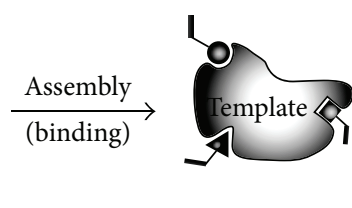

(ii)

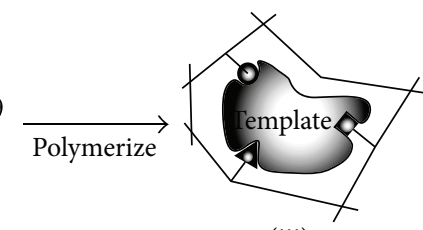

(iii)

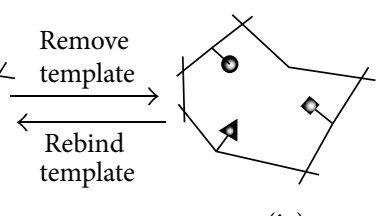

(iv)

FIGURE 27: Schematic diagram of the molecular imprinting process. Reprinted from [65], with permission from Elsevier.

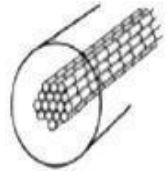

$\mathrm{SiO}_{2}$ sol
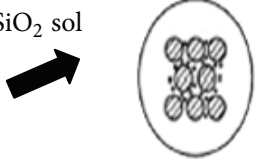

(1) Dry

(2) $600^{\circ} \mathrm{C}$

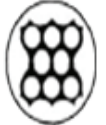

(I)

Macroporous silica

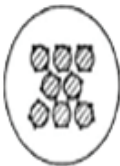

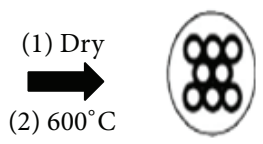

Route II

(II)

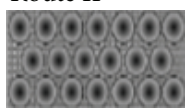

Meso/macroporous silica

FIGURE 28: Schematic depiction of two routes to the formation of organized macroporous inorganic frameworks using bacterial superstructural templates. Reprinted from [68], with permission from Nature Publishing Group.

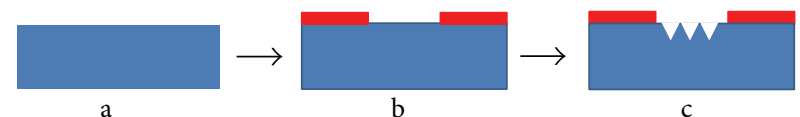

b
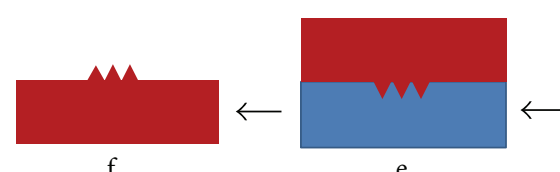

$\downarrow$

f

e

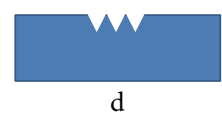

$\downarrow$

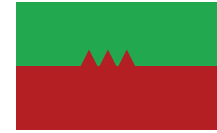

g
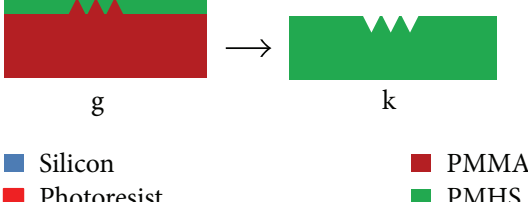

FIGURE 29: Schematic representation of the proposed generic fabrication process of porous polymers.

ions react with silicon to produce $\mathrm{SiF}_{4}$ gas. Dissociation of the gas phase at room temperature leaves behind a porous silicon surface. In this process, increasing the etching process time increases the overall size of the pores and the thickness of the porous silicon film. The chemical reaction for the etching of silicon by $\mathrm{XeF}_{2}$ is summarized by $\mathrm{Si}+2 \mathrm{XeF}_{2} \rightarrow \mathrm{SiF}_{4}+2 \mathrm{Xe}$. As a dry etching technique, there is no postfabrication drying step required, thus reducing the risk of damage to the newly formed porous surface [78].

$\mathrm{XeF}_{2}$ leaves behind porous silicon surfaces on top of the remaining bulk silicon with porous silicon layer thickness on the order of several hundreds of nanometers (600 to $700 \mathrm{~nm})$. The obtained porosity depends on the etching time. Figure $30(a)$ is a photograph of a silicon sample made porous selectively at the center. Figure 30(b) shows a scanning electron microscope image of porous silicon sample prepared using $\mathrm{XeF}_{2}$. The porosity of the porous silicon surface can be changed by changing the etching time in $\mathrm{XeF}_{2}$ [78].

5.2. Preparation of Porous Polymer. Porous polymers are conventionally fabricated with specific processes depending on the chemical structure of the polymer. Here, micromolding is the proposed technique to form porous polymers. The first molding step consists of making the complementary polymer by pouring polymethyl methacrylate (PMMA) on the porous silicon template as illustrated in Figure 29(e). PMMA was left 


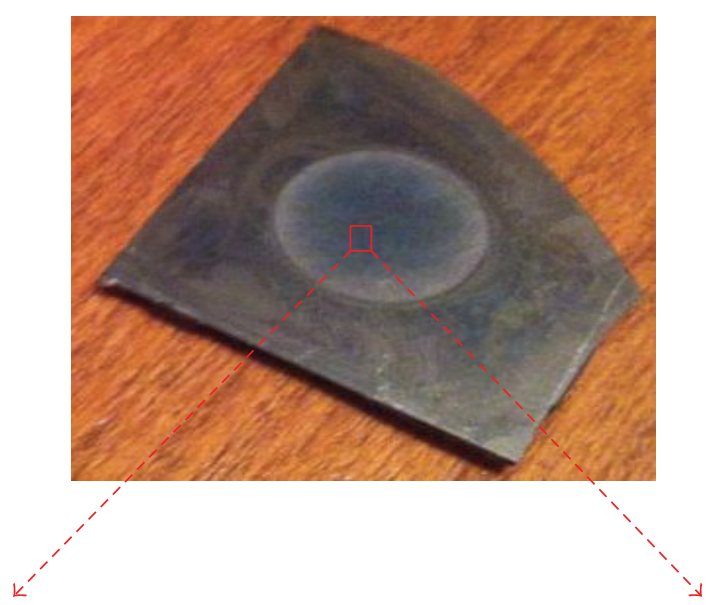

(a)

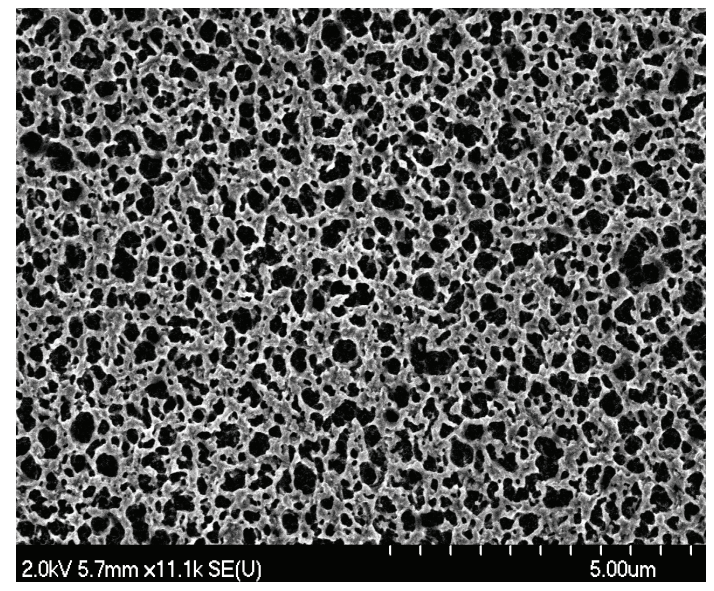

(b)

FIgURE 30: (a) Porous silicon template. (b) Scanning electron micrograph of a porous silicon template textured with $\mathrm{XeF}_{2}$.

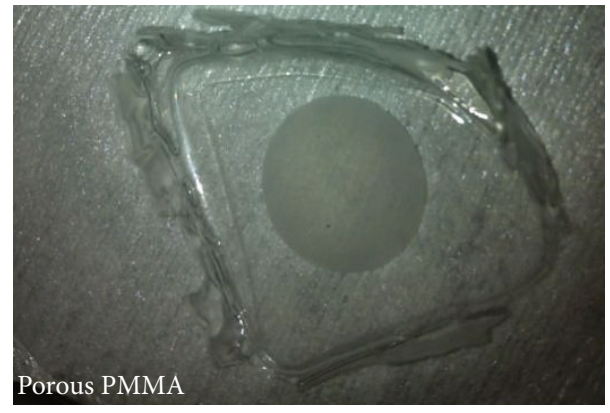

(a)

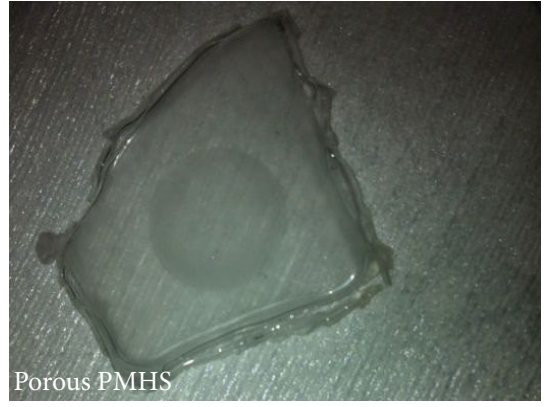

(b)

Figure 31: (a) Porous PMMA sample. (b) Porous PMHS sample.

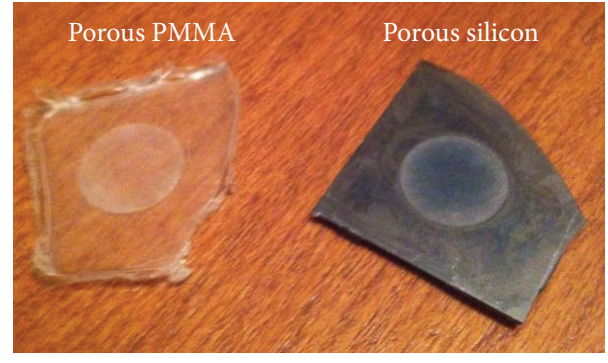

FIgURE 32: Porous PMMA and porous silicon samples.

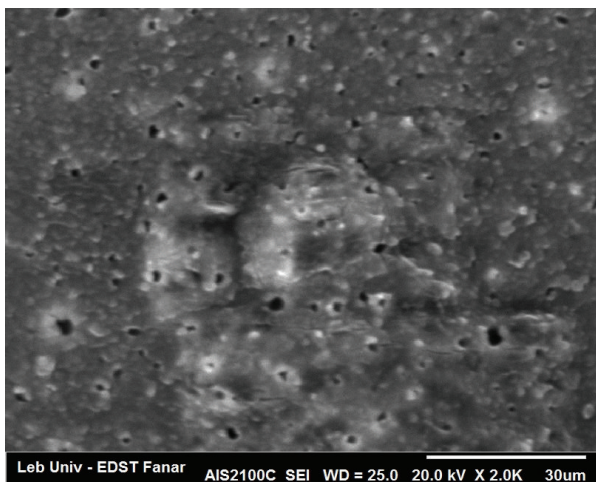

FIgURE 33: Scanning electron micrograph of a porous PMHS.

for 24 hours at room temperature to get cured. Figure 31(a) shows a porous PMMA peeled off after curing. Porous PMMA is the complement of the porous silicon template. The final porous polymer, in this case polymethyl hydrosiloxane (PMHS), is now poured on the PMMA template as depicted in Figure $29(\mathrm{~g})$. PMHS requires $48-72$ hours at $110^{\circ} \mathrm{C}$ to get cured with no secondary additives. The peeled off porous PMHS, identical to the porous silicon template, is shown in Figure 31(b). Both porous PMHS and silicon are shown in Figure 32. Figure 33 shows a scanning electron microscope image of porous PMHS sample prepared by this generic process.

\section{Conclusions}

The paper aimed to give an overview of the commonly used fabrication processes used to develop porous polymers for a wide variety of applications. The details provided 
in this review represent a solid cornerstone to researchers interested in working on porous polymers. It summarizes the advantages and disadvantages of each technique and gives insight into the selection of the appropriate process for a specific polymer. A new fabrication process is also presented in this review to provide a generic fabrication process that can be applied to all liquid polymers to make their external surface porous. As an example, porous PMHS structure was developed using porous silicon scaffolds. The proposed process is simple, straightforward, and flexible since porous polymers with different porosities can be obtained by simply changing the porosity of the porous silicon template. Future work will include further characterization of the porous PMHS using SEM microscopy and the development of new types of porous polymers for specific applications.

\section{Conflict of Interests}

The authors declare that there is no conflict of interests regarding the publication of this paper.

\section{Acknowledgments}

The current project is supported by the National Council for Scientific Research, Lebanon. The authors would also like to acknowledge the assistance of the McGill's Nanotools and Microfabrication Laboratory in preparing the porous silicon samples.

\section{References}

[1] V. I. Raman and G. R. Palmese, "Nanoporous polymers-design and applications," in Nanomaterials Handbook, Y. Gogotsi, Ed., CRC Press, New York, NY, USA, 2006.

[2] M. Ulbricht, "Advanced functional polymer membranes," Polymer, vol. 47, no. 7, pp. 2217-2262, 2006.

[3] F. Gallucci, A. Basile, and F. I. Hai, "Introduction-a review of membrane reactors," in Membranes for Membrane Reactors: Preparation, Optimization and Selection, A. Basile and F. Gallucci, Eds., pp. 1-60, John Wiley \& Sons:, Chichester, UK, 2011.

[4] M. U. H. Susanto, "Porous flat sheet, hollow fibre and capsule membranes by phase separation of polymer solutions," in Membranes for Membrane Reactors: Preparation, Optimization and Selection, A. B. F. Gallucci, Ed., John Wiley \& Sons, London, UK, 2011.

[5] A. G. Mikos and J. S. Temenoff, "Formation of highly porous biodegradable scaffolds for tissue engineering," Electronic Journal of Biotechnology, vol. 3, no. 2, pp. 1-6, 2000.

[6] B. Dhandayuthapani, Y. Yoshida, T. Maekawa, and D. S. Kumar, "Polymeric scaffolds in tissue engineering application: a review," International Journal of Polymer Science, vol. 2011, Article ID 290602, 19 pages, 2011.

[7] C. Gualandi, Porous Polymeric Bioresorbable Scaffolds for Tissue Engineering, Springer, 2011.

[8] K. Rezwan, Q. Z. Chen, J. J. Blaker, and A. R. Boccaccini, "Biodegradable and bioactive porous polymer/inorganic composite scaffolds for bone tissue engineering," Biomaterials, vol. 27, no. 18, pp. 3413-3431, 2006.

[9] R. Langer and J. P. Vacanti, “Tissue engineering," Science, vol. 260, no. 5110, pp. 920-926, 1993.
[10] M. S. Silverstein, N. R. Cameron, and M. A. Hillmyer, Porous Polymers, Wiley, 2011.

[11] F. B. Calleja and Z. Roslaniec, Block Copolymers, Taylor \& Francis, 2000.

[12] M. Cetinkaya, Synthesis and Characterization of Nanostructured Poly(p-xylylene) Films, ProQuest, 2008.

[13] N. J. Manjooran and G. R. Pickrell, "Biologically self-assembled porous polymers," Journal of Materials Processing Technology, vol. 168, no. 2, pp. 225-229, 2005.

[14] S. Michael, N. R. C. Silverstein, and M. A. Hillmyer, Porous Polymers, Wiley, 2011.

[15] D. Zhao, Y. Wan, and W. Zhou, Ordered Mesoporous Materials, Wiley, 2013.

[16] Q. Xu, Nanoporous Materials: Synthesis and Applications, Taylor \& Francis, 2013.

[17] O. M. Yaghi, G. Li, and H. Li, "Selective binding and removal of guests in a microporous metal-organic framework," Nature, vol. 378, no. 6558, pp. 703-706, 1995.

[18] M. A. A. Musa, C.-Y. Yin, and R. M. Savory, "Synthesis and textural characterization of covalent organic framework-1: comparison of pore size distribution models," Materials Chemistry and Physics, vol. 123, no. 1, pp. 5-8, 2010.

[19] A. P. Côté, A. I. Benin, N. W. Ockwig, M. O’Keeffe, A. J. Matzger, and O. M. Yaghi, "Porous, crystalline, covalent organic frameworks," Science, vol. 310, no. 5751, pp. 1166-1170, 2005.

[20] H. Furukawa and O. M. Yaghi, "Storage of hydrogen, methane, and carbon dioxide in highly porous covalent organic frameworks for clean energy applications," Journal of the American Chemical Society, vol. 131, no. 25, pp. 8875-8883, 2009.

[21] A. K. Bo Mattiasson and I. Y. Galaev, Eds., Macroporous Polymers Production Properties and Biotechnological/Biomedical Applications, CRC Press, Taylor \& Francis Group, 2010.

[22] H. Small, Ion Chromatography, Springer, Boston, Mass, USA, 1989.

[23] B. Mattiasson, A. Kumar, and I. Galaev, Macroporous Polymers: Production Properties and Biotechnological/Biomedical Applications, CRC Press/Taylor \& Francis, 2010.

[24] A. Salerno, E. Di Maio, S. Iannace, and P. A. Netti, "Solidstate supercritical $\mathrm{CO}_{2}$ foaming of PCL and PCL-HA nanocomposite: effect of composition, thermal history and foaming process on foam pore structure," The Journal of Supercritical Fluids, vol. 58, no. 1, pp. 158-167, 2011.

[25] H.-P. Hentze and M. Antonietti, "Porous polymers and resins for biotechnological and biomedical applications," Reviews in Molecular Biotechnology, vol. 90, no. 1, pp. 27-53, 2002.

[26] I. Tsivintzelis, A. G. Angelopoulou, and C. Panayiotou, "Foaming of polymers with supercritical $\mathrm{CO}_{2}$ : an experimental and theoretical study," Polymer, vol. 48, no. 20, pp. 5928-5939, 2007.

[27] A. Baiker, "Supercritical fluids in heterogeneous catalysis," Chemical Reviews, vol. 99, no. 2-3, pp. 453-473, 1999.

[28] J. A. Darr and M. Poliakoff, "New directions in inorganic and metal-organic coordination chemistry in supercritical fluids," Chemical Reviews, vol. 99, no. 2-3, pp. 495-541, 1999.

[29] Z. Xing, M. Wang, G. Du et al., "Preparation of microcellular polystyrene/polyethylene alloy foams by supercritical $\mathrm{CO}_{2}$ foaming and analysis by X-ray microtomography," The Journal of Supercritical Fluids, vol. 82, pp. 50-55, 2013.

[30] E. Reverchon and S. Cardea, "Production of controlled polymeric foams by supercritical $\mathrm{CO}_{2}$," The Journal of Supercritical Fluids, vol. 40, no. 1, pp. 144-152, 2007. 
[31] S. G. Kazarian, "Polymer processing with supercritical fluids," Polymer Science, vol. 42, no. 1, pp. 78-101, 2000.

[32] Animal Classification, http://lrrpublic.cli.det.nsw.edu.au/lrrSecure/Sites/LRRView/7397/applets/Living_Things_Database/livingthings/pdf/ltlesson12.pdf.

[33] B. Subia, J. Kundu, and S. C. Kundu, "Biomaterial scaffold fabrication techniques for potential tissue engineering applications," in Tissue Engineering, D. Eberli, Ed., InTech, 2010.

[34] J. Kiefer, J. G. Hilborn, and J. L. Hedrick, "Chemically induced phase separation: a new technique for the synthesis of macroporous epoxy networks," Polymer, vol. 37, no. 25, pp. 5715-5725, 1996.

[35] T.-H. Young, L.-P. Cheng, D.-J. Lin, L. Fane, and W.-Y. Chuang, "Mechanisms of PVDF membrane formation by immersionprecipitation in soft (1-octanol) and harsh (water) nonsolvents," Polymer, vol. 40, no. 19, pp. 5315-5323, 1999.

[36] M. di Luccio, R. N. Nobrega, and C. P. Borges, "Microporous anisotropic phase inversion membranes from bisphenol-A polycarbonate: study of a ternary system," Polymer, vol. 41, no. 11, pp. 4309-4315, 2000.

[37] Y. S. Nam and T. G. Park, "Biodegradable polymeric microcellular foams by modified thermally induced phase separation method," Biomaterials, vol. 20, no. 19, pp. 1783-1790, 1999.

[38] H. Matsuyama, M. Teramoto, M. Kuwana, and Y. Kitamura, "Formation of polypropylene particles via thermally induced phase separation," Polymer, vol. 41, no. 24, pp. 8673-8679, 2000.

[39] J. Li, Z. Du, H. Li, and C. Zhang, "Porous epoxy monolith prepared via chemically induced phase separation," Polymer, vol. 50, no. 6, pp. 1526-1532, 2009.

[40] J. Kiefer, J. L. Hedrick, and J. G. Hilborn, "Macroporous thermosets by chemically induced phase separation," Advances in Polymer Science, vol. 147, pp. 161-247, 1999.

[41] H. Zhang, "Porous materials by templating of small liquid drops," in Hierarchically Structured Porous Materials: From Nanoscience to Catalysis, Separation, Optics, Energy, and Life Science, John Wiley \& Sons, Weinheim, Germany, 2011.

[42] R. Butler, I. Hopkinson, and A. I. Cooper, "Synthesis of porous emulsion-templated polymers using high internal phase $\mathrm{CO}_{2}$ in-water emulsions," Journal of the American Chemical Society, vol. 125, no. 47, pp. 14473-14481, 2003.

[43] N. R. Cameron and D. C. Sherrington, "High internal phase emulsions (HIPEs) - structure, properties and use in polymer preparation," Advances in Polymer Science, vol. 126, pp. 162-214, 1996.

[44] I. Pulko and P. Krajnc, "High internal phase emulsion templating - a path to hierarchically porous functional polymers," Macromolecular Rapid Communications, vol. 33, no. 20, pp. 1731-1746, 2012.

[45] P. Hainey, I. M. Huxham, B. Rowatt, D. C. Sherrington, and L. Tetley, "Synthesis and ultrastructural studies of styrenedivinylbenzene polyhipe polymers," Macromolecules, vol. 24, no. 1, pp. 117-121, 1991.

[46] T. P. Hoar and J. H. Schulman, "Transparent water-in-oil dispersions: the oleopathic hydro-micelle," Nature, vol. 152, no. 3847, pp. 102-103, 1943.

[47] F. Candau, "Microemulsion polymerization," NATO ASI Series, vol. 335, pp. 127-140, 1997.

[48] P. A. Winsor, "Hydrotropy, solubilisation and related emulsification processes," Transactions of the Faraday Society, vol. 44, pp. 376-398, 1948.
[49] S. K. Mehta and G. Kaur, "Microemulsions: thermodynamic and dynamic properties," in Thermodynamics, chapter 18, pp. 381-402, InTech, 2011.

[50] L. M. Gan, T. D. Li, C. H. Chew, W. K. Teo, and L. H. Gan, "Microporous polymeric materials from polymerization of zwitterionic microemulsions," Langmuir, vol. 11, no. 9, pp. 3316-3320, 1995.

[51] T. H. Chieng, L. M. Gan, C. H. Chew et al., "Microporous polymeric materials by microemulsion polymerization: effect of surfactant concentration," Langmuir, vol. 11, no. 9, pp. 33213326, 1995.

[52] G. Widawski, M. Rawiso, and B. François, "Self-organized honeycomb morphology of star-polymer polystyrene films," Nature, vol. 369, no. 6479, pp. 387-389, 1994.

[53] M. L. K. Hoa, M. Lu, and Y. Zhang, "Preparation of porous materials with ordered hole structure," Advances in Colloid and Interface Science, vol. 121, no. 1-3, pp. 9-23, 2006.

[54] O. D. Velev and A. M. Lenhoff, "Colloidal crystals as templates for porous materials," Current Opinion in Colloid \& Interface Science, vol. 5, no. 1-2, pp. 56-63, 2000.

[55] D. Nicholas and A. S. Petkovich, "Colloidal crystal templating approaches to materials with hierarchical porosity," in Hierarchically Structured Porous Materials: From Nanoscience to Catalysis, Separation, Optics, Energy, and Life Science, pp. 55129, Wiley-VCH, Weinheim, Germany, 2011.

[56] S. H. Park and Y. Xia, "Fabrication of three-dimensional macroporous membranes with assemblies of microspheres as templates," Chemistry of Materials, vol. 10, no. 7, pp. 1745-1747, 1998.

[57] B. Gates, Y. Yin, and Y. Xia, "Fabrication and characterization of porous membranes with highly ordered three-dimensional periodic structures," Chemistry of Materials, vol. 11, no. 10, pp. 2827-2836, 1999.

[58] D. R. Sadoway, "Block and graft copolymer electrolytes for highperformance, solid-state, lithium batteries," Journal of Power Sources, vol. 129, no. 1, pp. 1-3, 2004.

[59] M. Li, C. A. Coenjarts, and C. K. Ober, "Patternable block copolymers," in Block Copolymers II, vol. 190 of Advances in Polymer Science, pp. 183-226, Springer, Berlin, Germany, 2005.

[60] M. Park, C. Harrison, P. M. Chaikin, R. A. Register, and D. H. Adamson, "Block copolymer lithography: periodic arrays of $10^{11}$ holes in 1 square centimeter," Science, vol. 276, no. 5317, pp. 1401-1404, 1997.

[61] J.-S. Lee, A. Hirao, and S. Nakahama, "Polymerization of monomers containing functional silyl groups. 7. Porous membranes with controlled microstructures," Macromolecules, vol. 22, no. 6, pp. 2602-2606, 1989.

[62] W. A. Phillip, J. Rzayev, M. A. Hillmyer, and E. L. Cussler, "Gas and water liquid transport through nanoporous block copolymer membranes," Journal of Membrane Science, vol. 286, no. 1-2, pp. 144-152, 2006.

[63] S. Y. Yang, I. Ryu, H. Y. Kim, J. K. Kim, S. K. Jang, and T. P. Russell, "Nanoporous membranes with ultrahigh selectivity and flux for the filtration of viruses," Advanced Materials, vol. 18, no. 6, pp. 709-712, 2006.

[64] S. A. Jenekhe and X. L. Chen, "Self-assembly of ordered microporous materials from rod-coil block copolymers," Science, vol. 283, no. 5400, pp. 372-375, 1999.

[65] C. Alexander, L. Davidson, and W. Hayes, "Imprinted polymers: artificial molecular recognition materials with applications in synthesis and catalysis," Tetrahedron, vol. 59, no. 12, pp. 20252057, 2003. 
[66] J. Steinke, D. C. Sherrington, and I. R. Dunkin, "Imprinting of synthetic polymers using molecular templates," Advances in Polymer Science, vol. 123, pp. 81-125, 1995.

[67] P. A. G. Cormack and K. Mosbach, "Molecular imprinting: recent developments and the road ahead," Reactive \& Functional Polymers, vol. 41, no. 1, pp. 115-124, 1999.

[68] S. A. Davis, S. L. Burkett, N. H. Mendelson, and S. Mann, "Bacterial templating of ordered macrostructures in silica and silica-surfactant mesophases," Nature, vol. 385, no. 6615, pp. 420-423, 1997.

[69] F. C. Meldrum and R. Seshadri, "Porous gold structures through templating by echinoid skeletal plates," Chemical Communications, no. 1, pp. 29-30, 2000.

[70] D. Yang, L. Qi, and J. Ma, "Eggshell membrane templating of hierarchically ordered macroporous networks composed of $\mathrm{TiO}_{2}$ tubes," Advanced Materials, vol. 14, no. 21, pp. 1543-1546, 2002.

[71] G. Cook, P. L. Timms, and C. Göltner-Spickermann, "Exact replication of biological structures by chemical vapor deposition of silica," Angewandte Chemie-International Edition, vol. 42, no. 5, pp. 557-559, 2003.

[72] S. R. Hall, H. Bolger, and S. Mann, "Morphosynthesis of complex inorganic forms using pollen grain templates," Chemical Communications, vol. 9, no. 22, pp. 2784-2785, 2003.

[73] V. Valtchev, M. Smaihi, A.-C. Faust, and L. Vidal, "Biomineralsilica-induced zeolitization of Equisetum Arvense," Angewandte Chemie - International Edition, vol. 42, no. 24, pp. 27822785, 2003.

[74] Y. Shin, C. Wang, and G. J. Exarhos, "Synthesis of SiC ceramics by the carbothermal reduction of mineralized wood with silica," Advanced Materials, vol. 17, no. 1, pp. 73-77, 2005.

[75] J. Huang and T. Kunitake, "Nano-precision replication of natural cellulosic substances by metal oxides," Journal of the American Chemical Society, vol. 125, no. 39, pp. 11834-11835, 2003.

[76] Y. Shin, X. S. Li, C. Wang, J. R. Coleman, and G. J. Exarhos, "Synthesis of hierarchical titanium carbide from titania-coated cellulose paper," Advanced Materials, vol. 16, no. 14, pp. 1212$1215,2004$.

[77] N. Zhu and X. Chen, "Biofabrication of tissue scaffolds," in Advances in Biomaterials Science and Biomedical Applications, InTech, 2013.

[78] M. Hajj-Hassan, M. Cheung, and V. Chodavarapu, "Dry etch fabrication of porous silicon using xenon difluoride," Micro and Nano Letters, vol. 5, no. 2, pp. 63-69, 2010.

[79] M. Naddaf, F. Awad, and M. Soukeih, "Step voltage with periodic hold-up etching: a novel porous silicon formation," Materials Science and Engineering C, vol. 27, no. 4, pp. 832-836, 2007.

[80] S. Boughaba and K. Wang, "Fabrication of porous silicon using a gas etching method," Thin Solid Films, vol. 497, no. 1-2, pp. 8389, 2006.

[81] N. K. Ali, M. R. Hashim, A. Abdul Aziz, and I. Hamammu, "Method of controlling spontaneous emission from porous silicon fabricated using pulsed current etching," Solid-State Electronics, vol. 52, no. 2, pp. 249-254, 2008.

[82] A. B. Jaballah, M. Saadoun, M. Hajji, H. Ezzaouia, and B. Bessaïs, "Silicon dissolution regimes from chemical vapour etching: from porous structures to silicon grooving," Applied Surface Science, vol. 238, no. 1-4, pp. 199-203, 2004.
[83] I. H. Cho, D. H. Kim, S. B. Ha, and D. Y. Noh, "Photochemical wet etching of silicon by synchrotron white X-ray radiation," Thin Solid Films, vol. 515, no. 14, pp. 5736-5740, 2007.

[84] Y. X. Li, P. J. French, P. M. Sarro, and R. F. Wolffenbuttel, "SIMPLE - a technique of silicon micromachining using plasma etching," Sensors and Actuators, A: Physical, vol. 57, no. 3, pp. 223-232, 1996.

[85] C. C. Pereira, R. Nobrega, and C. P. Borges, "Membranes obtained by simultaneous casting of two polymer solutions," Journal of Membrane Science, vol. 192, no. 1-2, pp. 11-26, 2001.

[86] M. Li and C. K. Ober, "Block copolymer patterns and templates," Materials Today, vol. 9, no. 9, pp. 30-39, 2006. 

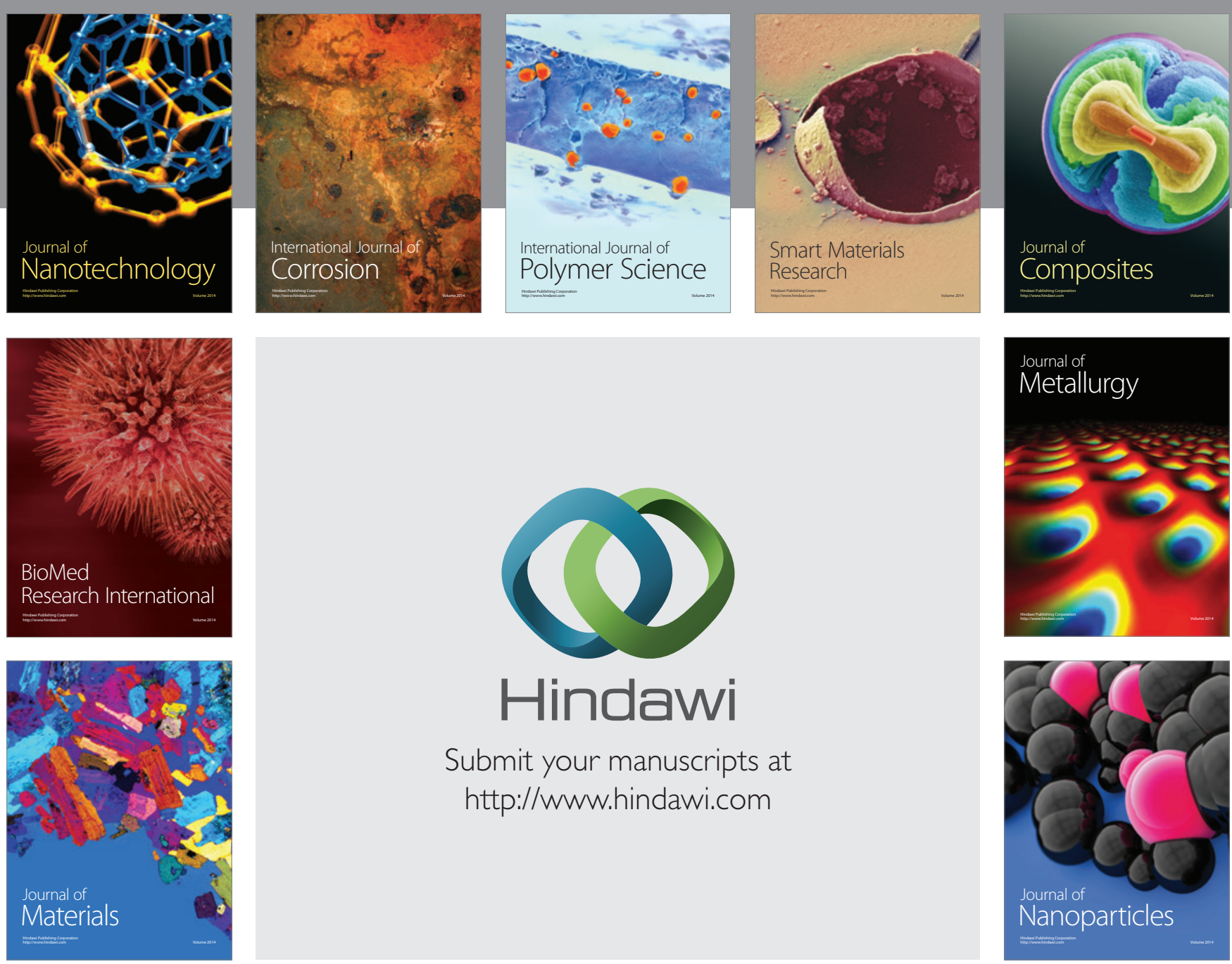

Submit your manuscripts at http://www.hindawi.com
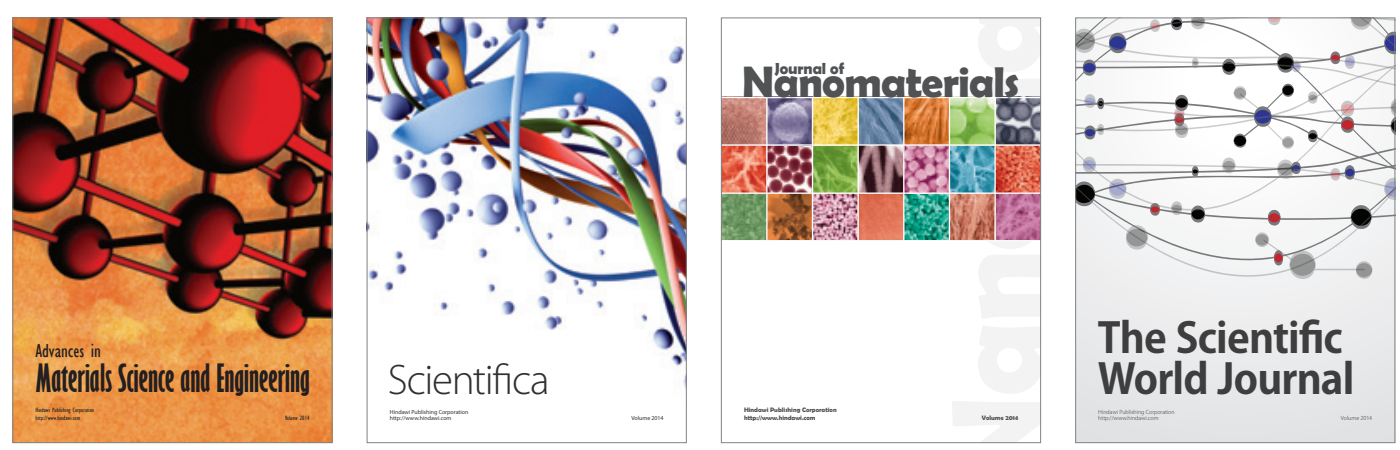

\section{The Scientific World Journal}
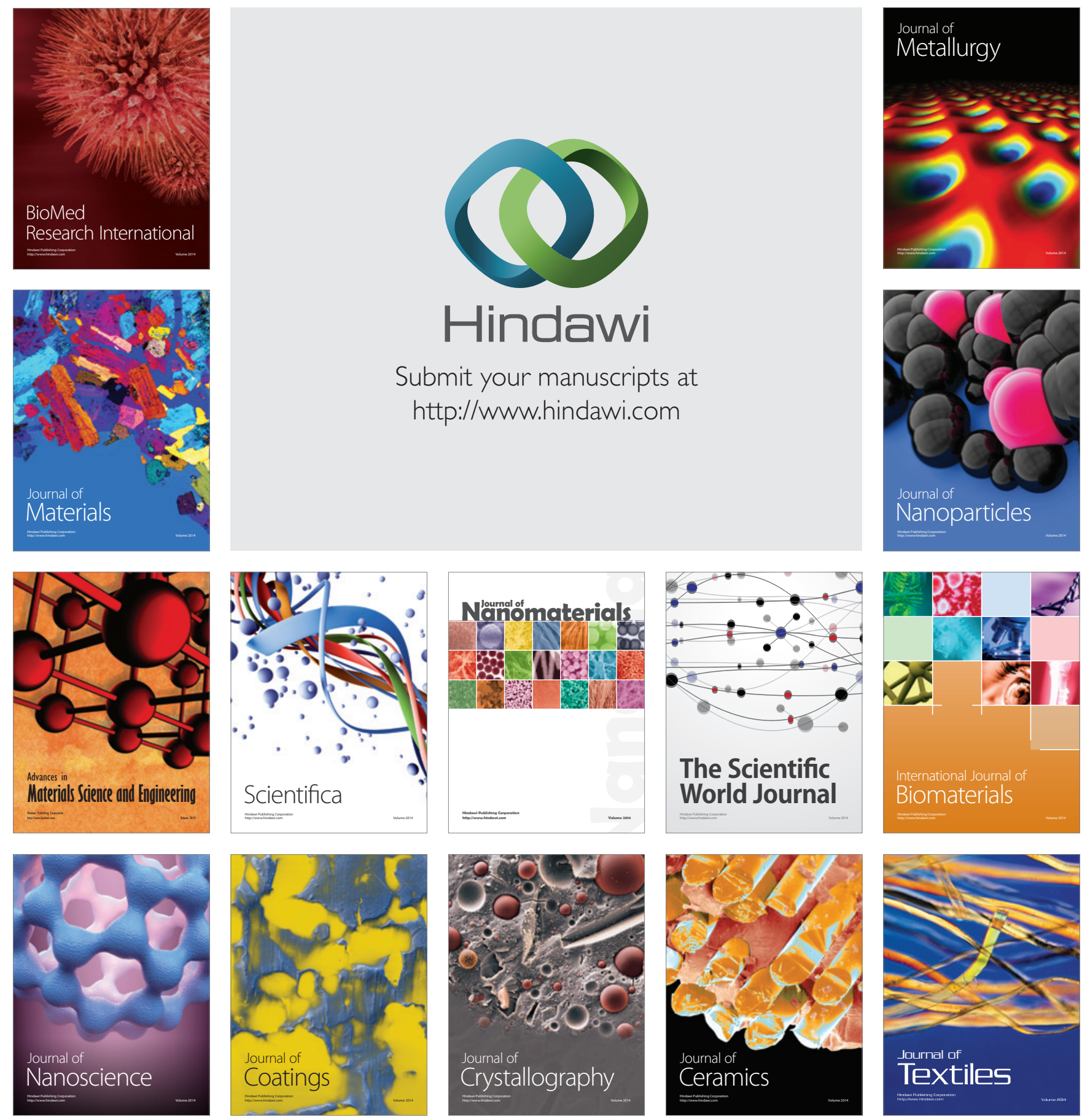